\title{
Effect of Preconditioning on the Extreme Climate Events in the Tropical Indian Ocean*
}

\author{
H. Annamalai and J. Potemra \\ International Pacific Research Center, University of Hawaii at Manoa, Honolulu, Hawaii \\ R. Murtugudde \\ ESSIC, University of Maryland, College Park, College Park, Maryland \\ J. P. MCCREARY \\ International Pacific Research Center, University of Hawaii at Manoa, Honolulu, Hawaii
}

(Manuscript received 12 March 2004, in final form 29 March 2005)

\begin{abstract}
Sea surface temperature observations in the eastern equatorial Indian Ocean (EEIO) during the period 1950-2003 indicate that Indian Ocean dipole/zonal mode (IODZM) events are strong in two decades, namely, the 1960s and 1990s. Atmospheric reanalysis products in conjunction with output from an ocean model are examined to investigate the possible reason for the occurrence of strong IODZM events in these two decades. Specifically, the hypothesis that the mean thermocline in the EEIO is raised or lowered depending on the phase of Pacific decadal variability (PDV), preconditioning the EEIO to favor stronger or weaker IODZM activity, is examined. Diagnostics reveal that the EEIO is preconditioned by the traditional PDV signal (SVD1 of SST), deepening or shoaling the thermocline off south Java through its influence on the Indonesian Throughflow (ITF; oceanic teleconnection), and by residual decadal variability in the western and central Pacific (SVD2 of SST) that changes the equatorial winds over the Indian Ocean (atmospheric teleconnection). Both effects produce a background state that is either favorable or unfavorable for the thermocline-mixed layer interactions, and hence for the excitation of strong IODZM events. Collectively, SVD1 and SVD2 are referred to as PDV here.

This hypothesis is tested with a suite of ocean model experiments. First, two runs are carried out, forced by climatological winds to which idealized easterly or westerly winds are added only over the equatorial Indian Ocean. As might be expected, in the easterly (westerly) run a shallower (deeper) thermocline is obtained over the EEIO. Then, observed winds from individual years are used to force the model. In these runs, anomalously cool SST in the EEIO develops only during decades when the thermocline is anomalously shallow, allowing entrainment of colder waters into the mixed layer.

Since 1999 the PDV phase has changed, and consistent with this hypothesis the depth of the mean thermocline in the EEIO has been increasing. As a consequence, no IODZM developed during the El Niño of 2002, and only a weak cooling event occurred during the summer of 2003. This hypothesis likely also explains why some strong IODZM events occur in the absence of ENSO forcing, provided that PDV has preconditioned the EEIO thermocline to be anomalously shallow.
\end{abstract}

\section{Introduction}

a. Background

Recent studies point toward the existence of a natural mode of climate variability in the Indian Ocean,

\footnotetext{
* International Pacific Research Center Contribution Number 321 and School of Ocean and Earth Science and Technology Contribution Number 6575.
}

Corresponding author address: Dr. H. Annamalai, IPRC/ SOEST, University of Hawaii at Manoa, 1680 East-West Rd., Honolulu, HI 96822.

E-mail: hanna@hawaii.edu known either as the Indian Ocean dipole/zonal mode (IODZM; Reverdin et al. 1986; Murtugudde et al. 1998b; Saji et al. 1999; Webster et al. 1999; Behera et al. 1999; Murtugudde and Busalacchi 1999; Yu and Rienecker 1999, 2000). As part of this mode, sea surface temperature (SST) in the eastern equatorial Indian Ocean (EEIO; in the neighborhood of $10^{\circ} \mathrm{S}-0^{\circ}, 90^{\circ}-$ $110^{\circ} \mathrm{E}$ ) becomes anomalously cool during boreal summer and fall, weakening the overlying precipitation; this change in atmospheric heating forces an anticyclone in the lower atmosphere over the southeastern Indian Ocean as a Rossby wave response (e.g., Annamalai et al. 2003). The resulting winds increase upwelling off Sumatra and substantially alter the near-equatorial oce- 

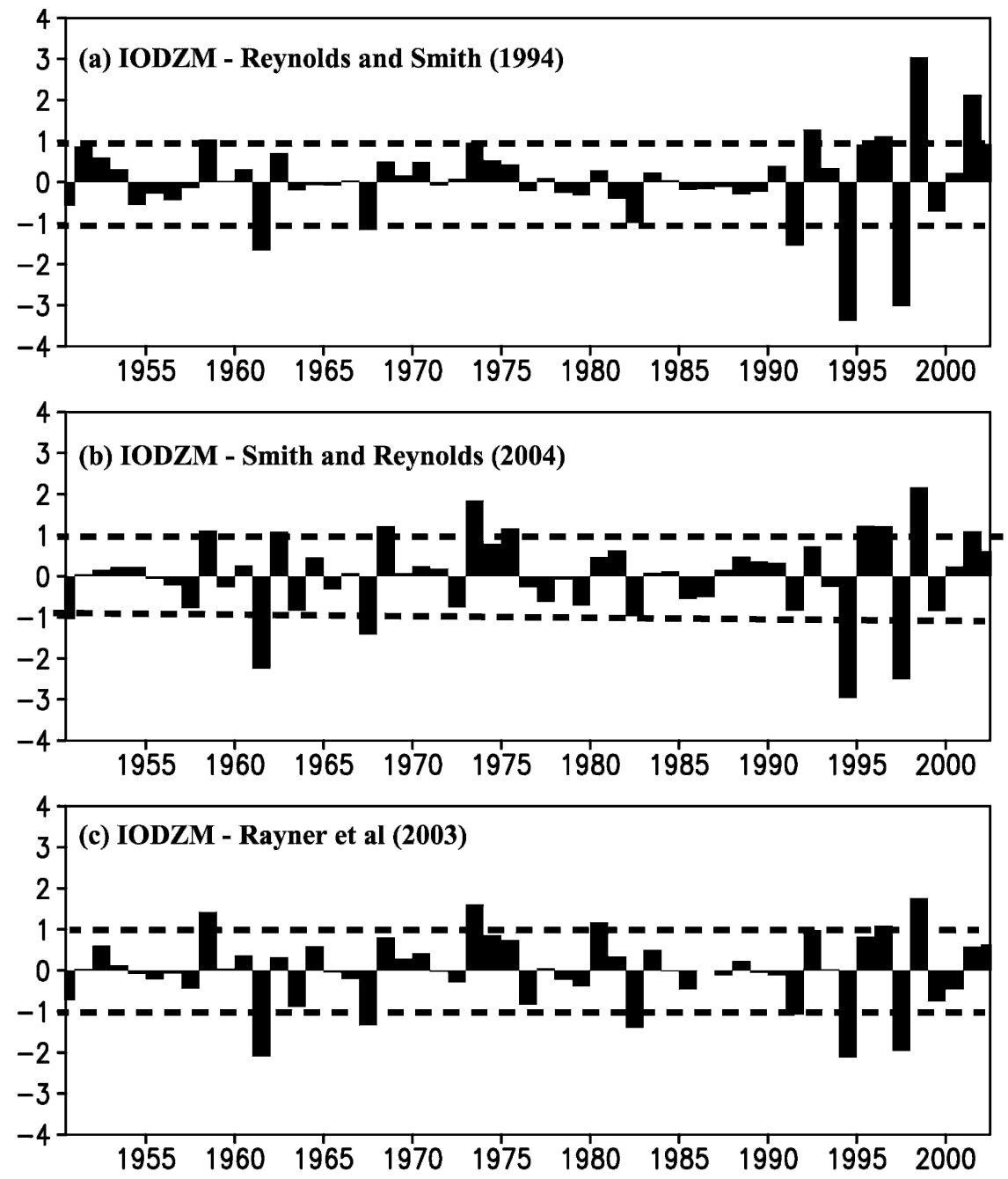

FIG. 1. Interannual SST anomalies (in std dev) over the EEIO $\left(10^{\circ} \mathrm{S}-0^{\circ}, 90^{\circ}-110^{\circ} \mathrm{E}\right)$ averaged during Jun-Nov from three different SST products: (a) Reynolds and Smith (1994), (b) Smith and Reynolds (2004), and (c) HadISST of Rayner et al. (2003). The dotted horizontal lines correspond to $1.0 \mathrm{std}$ dev.

anic thermal structure and circulation (e.g., Reppin et al. 1999; Vinaychandran et al. 1999; Murtugudde et al. 2000). As a result, there is significant correlation between SST and thermocline variation off Java and Sumatra during boreal summer and fall (e.g., Murtugudde et al. 1998b). All these changes are indicative of positive feedback between the atmosphere and the ocean in the equatorial Indian Ocean, in a manner similar to that proposed for the equatorial Pacific by Bjerknes (1969).

As a measure of the IODZM, Fig. 1a plots the interannual SST anomalies during June-November averaged over the region $10^{\circ} \mathrm{S}-0^{\circ}, 90^{\circ}-110^{\circ} \mathrm{E}$, as determined from Reynolds and Smith (1994; Fig. 1a), Smith and Reynolds (200; Fig. 1b), and the Hadley Centre interpolated SST (HadISST) dataset of Rayner et al. (2003;
Fig. 1c; details of the data are given in section 2). The three SST indices show that during the last four-five decades, almost all of the strong IODZM events with amplitudes close to or greater than one standard deviation occurred during the 1960s and 1990s, the sole exception being the 1982 event. (For convenience, throughout the paper we refer to the period 1960-69 as the $1960 \mathrm{~s}, 1970-77$ as the $1970 \mathrm{~s}, 1980-89$ as the $1980 \mathrm{~s}$, and 1990-97 as the 1990s). Typically, strong events are prominent in the decades of the 1960s and 1990s, and they are weak or quiescent at other times.

\section{b. Influence of PDV}

An obvious question that emerges from Fig. 1 is what causes the preference of strong IODZM events in certain decades? A possibility explored in this paper is that 
such occurrences result from forcing by Pacific decadal variability (PDV), through its influence on the depth of the EEIO thermocline. PDV has a time scale of about 20-30 yr, and the transitions between its opposite phases have been interpreted as regime shifts in the mean state of the climate system (e.g., Nitta and Yamada 1989; Latif and Barnett 1994; Nakamura et al. 1997; Solomon et al. 2003). Over the period 1950-2003, notable regime shifts in the North Pacific occurred during 1957-58, 1976-77, 1989-90 (Hare and Mantua 2000), and 1998-99 (McPhaden and Zhang 2004), with the 1976-77 climate shift receiving the most attention due to its impact on the North Pacific climate and ecosystem (Nakamura and Yamagata 1999; Hare and Mantua 2000; Schneider et al. 2002).

Many recent studies suggest a strong linkage between the Tropics and North Pacific at decadal time scales. Zhang et al. (1997) note that the decadal wind anomalies in the equatorial western-central Pacific resemble those of the interannual ENSO mode, and referred to it as "ENSO-like" decadal variability. From an extensive analysis of SST, rainfall, cloudiness, and sea level data for the period (1900-97), Deser et al. (2004) conclude that interdecadal variability of all these variables in the tropical Indo-Pacific region exhibits high coherency with sea level pressure over the North Pacific.

\section{c. Present study}

So far, nearly all studies that address the link between IODZM events and Pacific variability have focused on the relationship, or lack thereof, between IODZM and ENSO (e.g., Alan et al. 2001; Xie et al. 2002; Hastenrath 2002; Krishnamurthy and Kirtman 2003; Yamagata et al. 2003). By contrast in the present study, we investigate the importance of decadal variability in the North Pacific and in the western Pacific warm pool on the preference of strong IODZM events in certain decades. For this purpose, we utilize analyses of atmospheric reanalysis products and solutions to an ocean model. To elucidate the origin of the decadal wind anomalies over the equatorial Indian Ocean, we seek solutions from a simple atmospheric model.

Our main conclusions are that, depending on its phase, the traditional PDV signal derived from singular value decomposition (SVD1) of SST shoals (deepens) the thermocline off south Java through its influence on the Indonesian Throughflow (ITF; oceanic teleconnection) and that residual decadal variability captured by SVD2 of SST in the western and central Pacific preconditions the EEIO thermocline through changes in the equatorial winds over the Indian Ocean (atmospheric teleconnection). Both effects provide a background state that is either favorable or unfavorable for upwelling of cooler subsurface water, and hence the excitation of strong IODZM events. Of the two processes, however, the contribution from the atmospheric teleconnection is much stronger, and it is therefore given more emphasis in the present study. Since 1999 the phase of PDV has changed, and, consistent with our hypothesis, the EEIO mean thermocline has been deepening; as a consequence, no IODZM developed during the El Niño of 2002 and only a weak cooling event occurred during the summer of 2003.

The paper is organized as follows. Section 2 describes the data and the models used. Section 3 defines our measure of PDV and determines its influence on EEIO preconditioning. Section 4 examines the effects of EEIO preconditioning under a range of interannual forcings and discusses the validity of our hypothesis in the context of the tropical Indo-Pacific status during 2002 and 2003. Section 5 summarizes our conclusions.

\section{Data and model}

\section{a. Data}

Most of the data used in our study are taken from the National Centers for Environmental PredictionNational Center for Atmospheric Research (NCEPNCAR) renalyses products for the period 1950-2003 (Kalnay et al. 1996). The SST for the analysis period is taken from Reynolds and Smith (1994). To assess the robustness, we also used the new extended reconstruction SST of Smith and Reynolds (2004) and the HadISST of Rayner et al. (2003). The data from Smith and Reynolds (2004) uses the most recently available Comprehensive Ocean-Atmosphere Data Set (COADS) SST data and improved statistical methods that allow stable reconstruction using sparse data. The HadISST is reconstructed using a two-stage reduced space optimal interpolation procedure, followed by superposition of quality-improved gridded observations onto the reconstructions to restore local detail.

Various diagnostic studies have assessed the quality of atmospheric reanalyses in the Tropics, showing that the divergent part of the wind is strongly influenced by model heating (e.g., Annamalai et al. 1999). Recently, Kinter et al. (2004) attributed interdecadal changes in the divergent wind field in the NCEP-NCAR reanalysis to changes in the observing system and assimilation procedures. Since our focus is on decadal time scales, we compare the results from the NCEP-NCAR reanalysis with those from the European Centre for Medium-Range Weather Forecasts (ECMWF) 40-yr ReAnalysis (ERA-40), which is the most recent comprehensive analysis and the first to provide an alternative to NCEP-NCAR reanalysis prior to 1979 (Simmons et 
al. 2004). ERA-40 is available from September 1957 to August 2002 and more details can be found in Simmons et al. (2004).

Additionally, we use the thermocline depth information from the new ocean reanalysis product, the Simple Ocean Data Assimilation (SODA) Parallel Ocean Program (POP). The major change that distinguishes this reanalysis from previous SODA efforts is that the ocean model has changed, and is now at a much higher resolution. Briefly, the ocean model used is an intermediate resolution version of the POP code developed at the Los Alamos National Laboratories. The model's spatial domain is global in extent, with a grid that has a resolution of $0.4^{\circ}$ of longitude and $0.28^{\circ}$ of latitude. The model has 40 vertical levels, which vary in depth from $10 \mathrm{~m}$ at the surface to $250 \mathrm{~m}$ in the deep ocean. The model is forced with daily averaged winds from ERA40 reanalysis spanning the period from January 1958 to 2001. Surface freshwater flux for the period 1979-2001 is provided by a combination of Global Precipitation Climatology Project monthly merged product combined with evaporation obtained from bulk formula. Bulk formulas are also used for the surface heat flux. SST is assimilated from observations (not a relaxation). Details of the reanalysis are provided in an upcoming article by J. A. Carton and B. S. Giese (2005, personal communication).

\section{b. Models}

\section{1) OCEAN MODEL}

The model ocean is a reduced-gravity, primitive equation, sigma-coordinate model coupled to an advective atmospheric mixed-layer model (Chen et al. 1994). The model domain extends over the Indo-Pacific region: $55^{\circ} \mathrm{S}-45^{\circ} \mathrm{N}, 30^{\circ} \mathrm{E}-70^{\circ} \mathrm{W}$. The horizontal resolution is $0.3^{\circ}$ within $10^{\circ} \mathrm{S}-10^{\circ} \mathrm{N}$ increasing up to $0.75^{\circ}$ at $50^{\circ} \mathrm{S}$ and $45^{\circ} \mathrm{N}$. The longitudinal resolution is uniform at $0.5^{\circ}$ while the vertical resolution is of the order of $2 \mathrm{~m}$ below the mixed layer increasing up to 10 at $100 \mathrm{~m}$. There are 25 sigma layers in the vertical with five layers in the top $10 \mathrm{~m}$. The bottom of the active layers typically extends to about $1500 \mathrm{~m}$ in the Tropics. Surface heat fluxes are computed from the atmospheric mixed layer using model SST, with specified Earth Radiation Budget Experiment (ERBE) solar radiation, International Satellite Cloud Climatology Project (ISCCP) cloudiness, and Xie and Arkin (1996) precipitation; due to the lack of reliable long time series, we specify climatological monthly-mean values for these variables. Open boundaries in the north and south are relaxed to Levitus and Boyer (1994) climatological temperature and salinity profiles over a $5^{\circ}$ sponge layer. We note that the model has already been success-
TABLE 1. A list of the ocean model experiments discussed in the text.

\begin{tabular}{llr}
\hline \hline \multicolumn{1}{c}{ Expts } & \multicolumn{1}{c}{ Forcing } & $\begin{array}{c}\text { Time } \\
(\mathrm{yr})\end{array}$ \\
\hline INT & NCEP winds & 52 \\
CTL & Climate NCEP winds & 45 \\
EAST & CTL + Indian Ocean easterlies & 5 \\
WEST & CTL + Indian Ocean westerlies & 5 \\
EAST97 & EAST, then 1997 winds & 1 \\
WEST97 & WEST, then 1997 winds & 1 \\
CTL97 & CTL, then 1997 winds & 1 \\
EAST61 & EAST, then 1961 winds & 1 \\
WEST61 & WEST, then 1961 winds & 1 \\
EAST96 & EAST, then 1996 winds & 1 \\
WEST96 & WEST, then 1996 winds & 1 \\
EAST57 & EAST, then 57 winds & 1 \\
WEST57 & WEST, then 57 winds & 1 \\
\hline
\end{tabular}

fully used in a number of applications similar to ours. For example, it simulates well the seasonal-tointerannual variability of the ITF (Murtugudde et al. 1998a) and SST in the tropical Indian and Pacific Oceans (Murtugudde et al. 2000; Hackert et al. 2001).

A key model diagnostic is thermocline depth, $h(x, y$, $t$ ), which we measure by the position of the $24^{\circ} \mathrm{C}$ isotherm, a typical value for the upper thermocline in the EEIO. As indicated by vertical modes of variability for propagating waves in the region, this isotherm is more representative of upper-ocean variations than midthermocline ones (Potemra et al. 2003). Moreover, its vertical motions measure the upwelling of cold water into the mixed layer more accurately than the $20^{\circ} \mathrm{C}$ isotherm, which is typically used to measure thermoclinedepth variations in other regions.

Table 1 lists the experiments that we report and their respective wind forcings. The model was initially "spun up" for 45 yr with climatological, daily wind stress from the NCEP-NCAR reanalysis (control or CTL run). The "interannual" run (INT) was initialized by the spun up run and forced with interannually varying, daily mean, NCEP reanalysis winds. Thus, the interannual variability in INT is driven by interannual wind stresses, which in turn affect the latent and sensible heat fluxes through their influence on wind speed, and these forcings generate realistic SST anomalies in both oceans. The other test runs are extensions forced by climatological winds plus specified anomalies described below. Since the model is spun up for $40 \mathrm{yr}$ with climatological winds it has no spinup or cold-start problems to imposed anomalies.

\section{2) Simple LiNEAR ATMOSPHERIC MODEL}

The model used here, which we refer to as the linear baroclinic model (LBM), is described in detail in Wa- 
tanabe and Kimoto (2000) and Watanabe and Jin (2003). It is a global, time-dependent, primitive equation model, linearized about the observed climatology derived from NCEP-NCAR reanalysis. Its horizontal resolution has triangular truncation 42 and there are 20 vertical levels in sigma coordinates. The model employs diffusion, Rayleigh friction, and Newtonian damping with a time scale of $(1 \text { day })^{-1}$ for $\sigma \geq 0.9$ and $\sigma \leq 0.03$, while $(30 \text { day })^{-1}$ is used elsewhere. The surface heat fluxes due to imposed SST anomalies and cumulus convection (Betts and Miller 1986) are parameterized, and a linearized moisture equation for the perturbation specific humidity is incorporated into the model. More details can be found in Watanabe and Jin (2003). In the LBM, the steady-state response may depend on the mean state about which linearization is sought (e.g., Gill 1980). Due to the decadal time scale nature of the signals, linearization about the annual-mean climatology is considered. The LBM is integrated for 30 days, and, with the dissipation terms adopted, the tropical response approaches a steady state after day 10 . The response at day 20 is analyzed.

\section{c. Data processing}

In the data and ocean model analyses reported here, monthly-mean climatologies are first calculated for the study period and anomalies are departures from them. Unless specified otherwise, decadal variability (periods $>8 \mathrm{yr}$ ) is separated from interannual variability (16 months to $8 \mathrm{yr}$ ) through harmonic analysis, in order to investigate possible links between the two time scales. It should be stressed here that since we have filtered out interannual variability, the decadal component is not contaminated by interannual IODZM events and therefore accounts for the slow variation in the climate system. Similar interpretations of this "linear" independency between interannual and decadal ENSO-like variability have been done in past studies (e.g., Pierce et al. 2000).

\section{Preconditioning of the EEIO thermocline}

In this section, we report several analyses that relate PDV to decadal variability in the Indo-Pacific Tropics. First, we perform a SVD analysis on decadal SST, surface winds, and $h$ from solution INT (section 3a) which identifies the importance of decadal signals from the Pacific in preconditioning the EEIO thermocline. Next, we construct a measure of EEIO preconditioning, $I$, based on $h$ (section 3b). Then, we force the LBM with SST patterns obtained from the SVD analysis to confirm the role of Pacific SST in forcing equatorial wind anomalies over the Indian Ocean (section 3c). Finally, we force the ocean model with idealized wind stress anomaly patterns over the equatorial Indian Ocean to create the EEIO preconditioning (section $3 \mathrm{~d}$ ).

\section{a. SVD analysis}

SVD is a fundamental matrix operation, a generalization of the diagonalization method that is performed in principal component (PC) analysis to matrices that are not square or symmetric. A unique benefit is that SVD of a cross-covariance matrix identifies, say from two data fields, pairs of spatial patterns that explain as much as possible of the mean-squared temporal covariance between the two fields. More details of the method are in Bretherton et al. (1992). In the present study, we have used three variables and the crosscovariance terms among them are given as input to the SVD analysis. To verify the results shown below, we carried out separate SVD analysis where crosscovariance terms between pairs of variables (viz., SST and surface winds, SST and $h$, and surface winds and $h$ ) are given as input, and the results (not shown) remain consistent with the ones discussed below.

\section{1) SVD RESUlts FROM PACIFIC SSTA}

Figures 2-4 show the spatial structures and PCs of the first two SVDs determined from low-pass-filtered (periods $>8 \mathrm{yr}$ ) SST data over the region $\left(20^{\circ} \mathrm{S}-60^{\circ} \mathrm{N}\right.$, $\left.120^{\circ} \mathrm{E}-80^{\circ} \mathrm{W}\right)$, surface winds over the Indo-Pacific Tropics $\left(30^{\circ} \mathrm{S}-30^{\circ} \mathrm{N}, 40^{\circ} \mathrm{E}-80^{\circ} \mathrm{W}\right)$, and $h$ over the tropical Indian Ocean $\left(20^{\circ} \mathrm{S}-20^{\circ} \mathrm{N}, 55^{\circ}-120^{\circ} \mathrm{E}\right)$. The eigenvalues of the first two SVD are well separated from higher-order patterns.

The SST spatial pattern of SVD1 (Fig. 2a) closely resembles the PDV in the North Pacific and ENSO-like decadal variability in the tropical Pacific that has been identified in many previous studies (e.g., Zhang et al. 1997; Nakamura et al. 1997; Pierce et al. 2000). The associated surface wind variability (Fig. $2 \mathrm{~b}$ ) in the Pacific depicts weakening of the easterly trade winds with a fair degree of equatorial symmetry, implying El Niño-like conditions. Other notable features in Fig. $2 b$ include low-level divergence over the equatorial west Pacific and enhanced easterly (westerly) wind anomalies to the south of Sumatran coast (equatorial western Indian Ocean). The covarying signal in $h$ (Fig. 2c) indicates a shallowing of the thermocline off south Java $\left(8^{\circ}-14^{\circ} \mathrm{S}, 105^{\circ}-120^{\circ} \mathrm{E}\right)$, and deepening in the entire equatorial Indian Ocean, with a maximum in the west. The associated time dependence, PC1 (Fig. 4a), undergoes a prominent switch from negative-to-positive values during the 1976-77 climate shift. Apart from this 
(a) SST

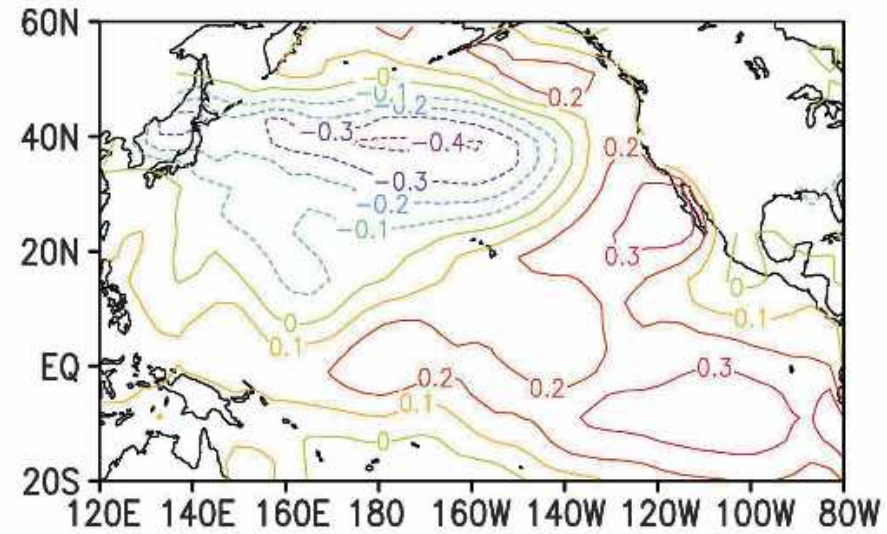

(b) Surface winds
$44.5 \%$

$19.2 \%$

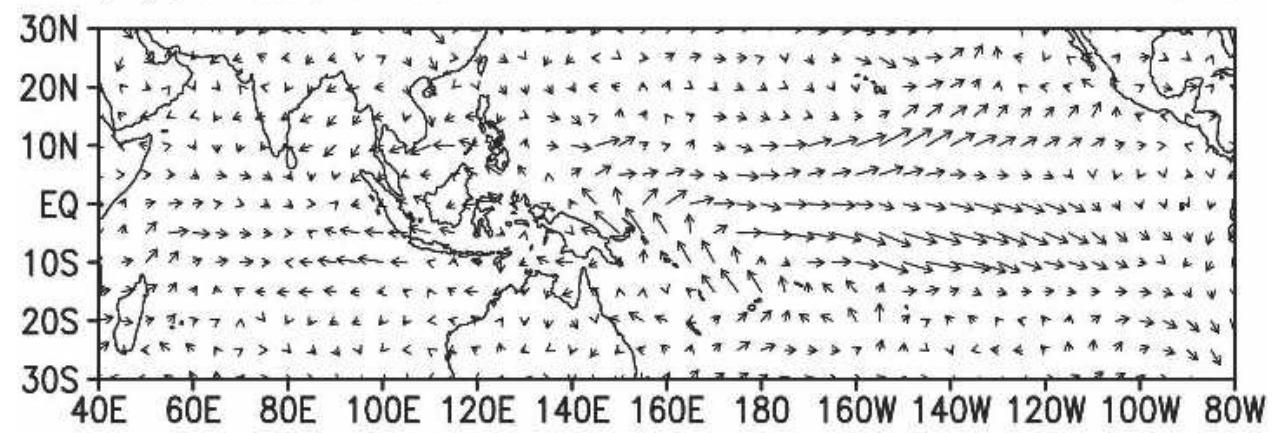

(c) $h$

$16.6 \% \quad \longrightarrow$

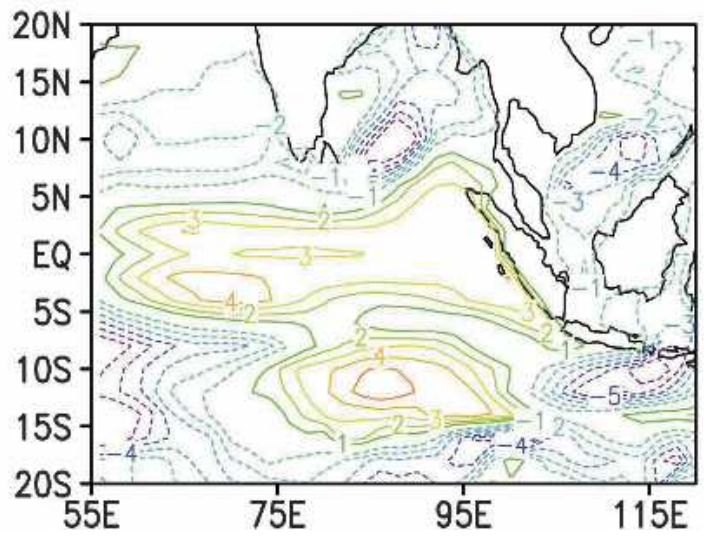

FIG. 2. Spatial patterns of SVD1 of (a) SST, (b) surface winds, and (c) $h$. The values are expressed as anomalies and the percent variance explained is also shown. The positive contours are in yellow and red, while negative contours are in green and purple. The contour interval is $0.1^{\circ} \mathrm{C}$ for SST and $1.0 \mathrm{~m}$ for $h$.

long-term change, a switch from positive-to-negative values is noticeable during the late 1990s coincident with the latest phase change in PDV (McPhaden and Zhang 2004). The implication is that SVD1 favors normal or La Niña-like (El Niño-like) conditions in the equatorial Pacific from 1950 to the mid-1970s and during the late 1990s (from the mid-1970s to 1998, and also during shorter-term periods of 1958-61 and 1967-69).

In the Indian Ocean, we can expect shallower-than- 
(a) SST

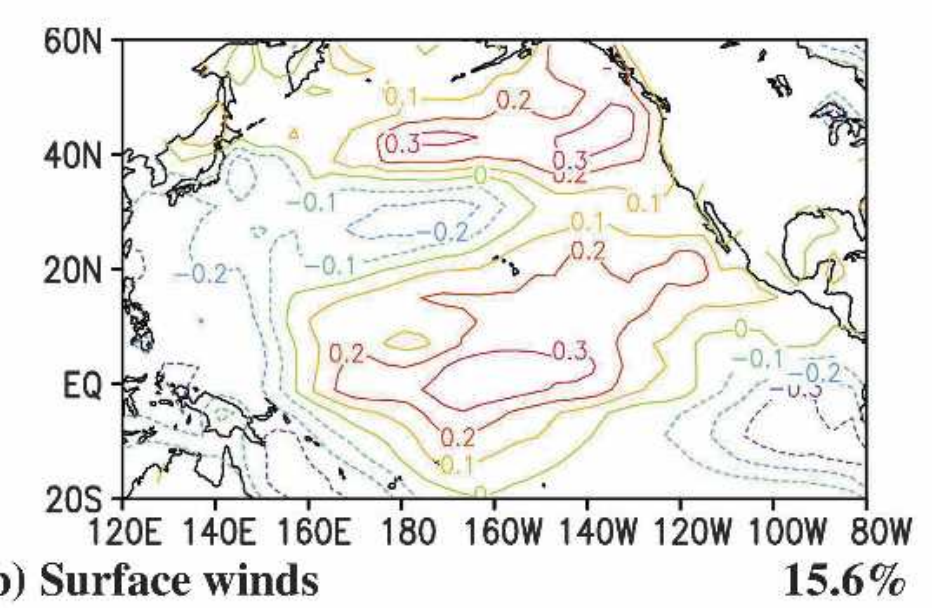

120E 140E 160E 180 160W 140W 120W 100W 80W

(b) Surface winds
$19.2 \%$

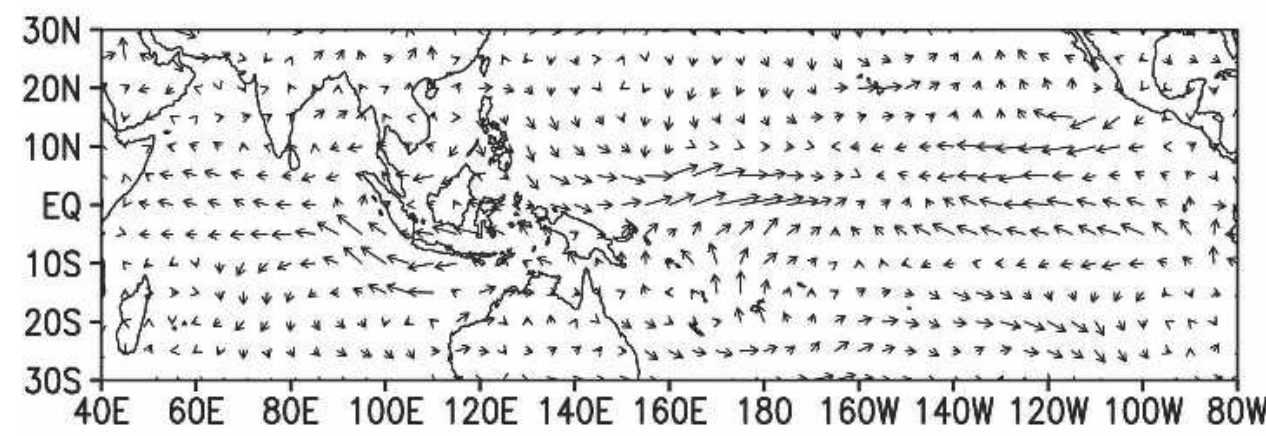

(c) $h$

$27.0 \%$
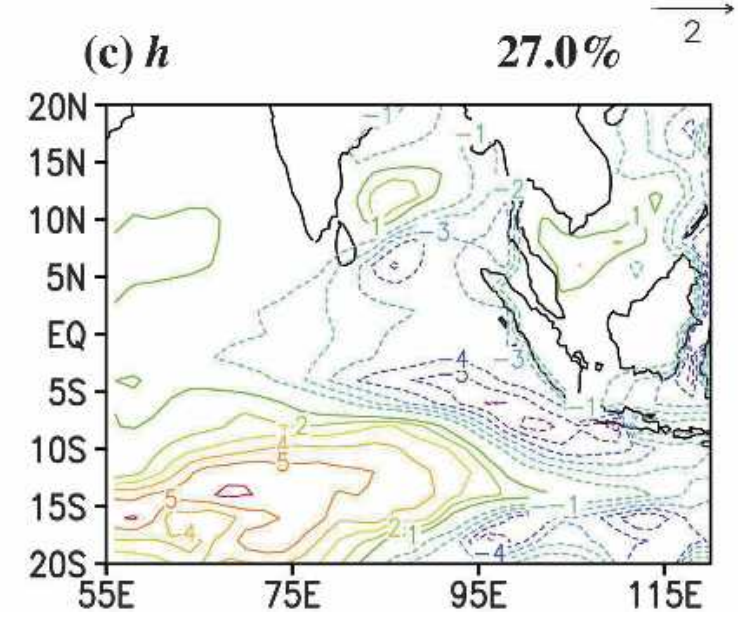

FIG. 3. Same as Fig. 2 but for SVD2. The contour interval for SST is $0.1^{\circ} \mathrm{C}$, and $1 \mathrm{~m}$ for $h$.

normal $h$ in the south Java region during 1976-97, and deeper than normal $h$ during most of 1950-76 and after 1998. The thermocline variations off south Java are particularly related to the variations in the ITF transport through the Lombak strait (e.g., Meyers 1996). The decadal variability of ITF transport in the model (Fig. 4c) shows a general decrease from the mid-1950s to early 1970 s with a large reduction in the late 1980s and early 1990s. This relationship suggests that the equatorial winds along the entire Pacific during El Niño-like conditions reduces the ITF and results in the $h$ shoaling off south Java, consistent with other studies (e.g., Susanto et al. 2001; Potemra et al. 2003).

The spatial SST pattern for SVD2 (Fig. 3a) and its temporal pattern (Fig. 4b, red line) taken together indicate that conditions favorable for La Niña (El Niño) 
(a) PC1
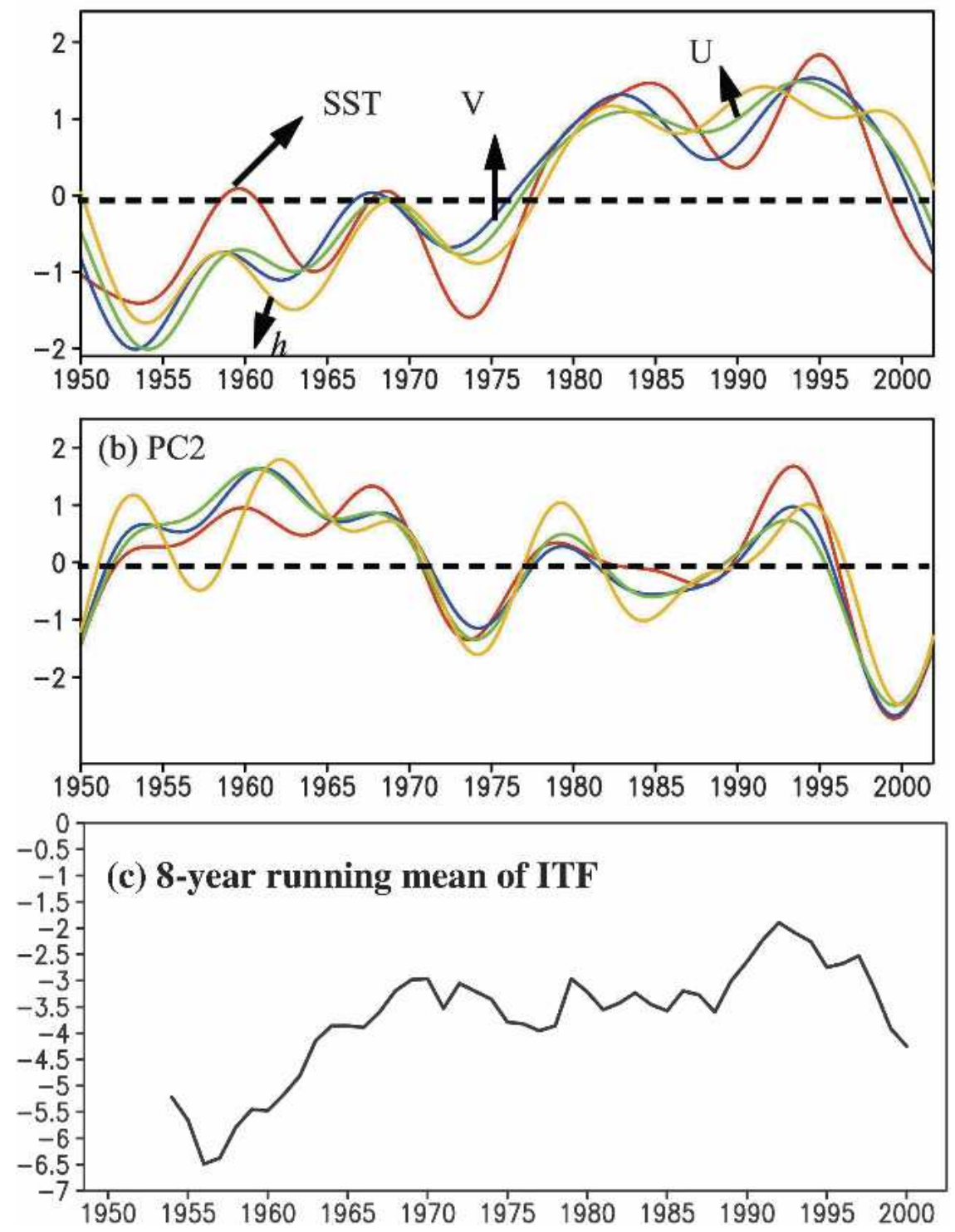

FIG. 4. The PC time series of the dominant SVD modes of SST (red line), surface winds ( $u$ : green line; $v$ : blue line), and $h$ (yellow line): (a) PC1 and (b) PC2. (c) The 8-yr running mean of the ITF transport from the ocean model. The negative values mean transport into the Indian Ocean and the unit is in $\mathrm{Sv}\left(1 \mathrm{~Sv} \equiv 10^{6} \mathrm{~m}^{3} \mathrm{~s}^{-1}\right)$.

were present in the equatorial western-central Pacific during 1972-88 and after 1998 (1952-70 and 1989-96). PC2 is positive, with maximum values during the 1960s. For our purposes, the important signature of SVD2 is its manifestation in the Tropics, particularly the signals over the warm pool and equatorial central Pacific that have not been identified in previous studies. Although there is no consistent lead-lag relationship between PC1 and PC2, we note that the latest phase change in PDV (1998-99) appears to have manifested in PC2 SST much earlier than in PC1 SST.
The surface wind variability of SVD2 (Fig. 3b) shows anomalous convergence in the central Pacific and divergence over the Maritime Continent, features indicative of a weakened Pacific Walker circulation, but one that does not extend into the eastern Pacific. The anomalous divergence near the Indonesian Islands, and easterly anomalies that extend across the entire equatorial Indian Ocean suggest weakening of the Indian Ocean Walker circulation. Finally, there is an anticyclonic circulation in the southeastern Indian Ocean associated with upwelling-favorable winds along the 
(a) SST

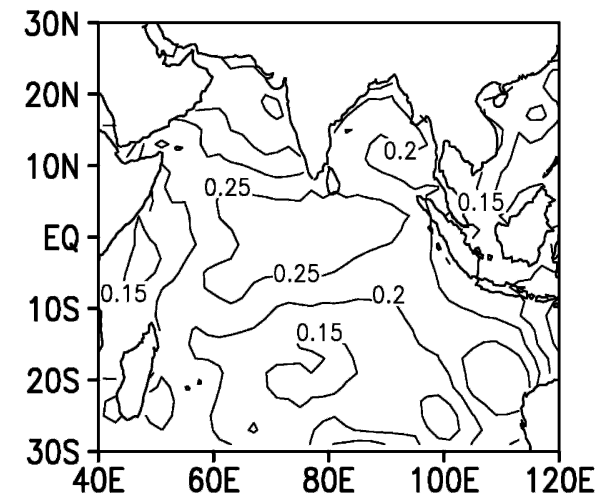

(b) Surface winds

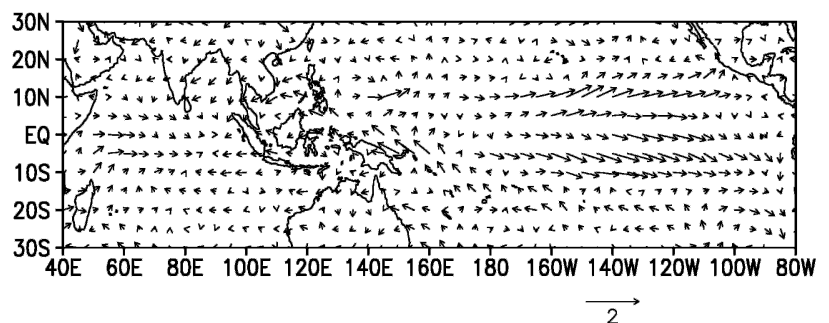

(c) SST

$11.7 \%$

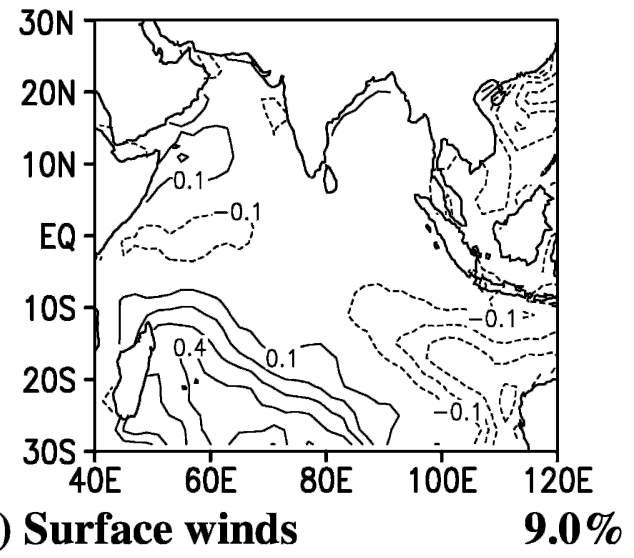

FIG. 5. Spatial patterns of (a), (b) SVD1 and (c), (d) SVD2 of SST and surface wind anomalies. Positive contours are yellow and red while negative contours are green and blue. SVD analysis is carried out with Indian Ocean SST anomalies and surface winds over the Indo-Pacific region.

Sumatran coast, similar to the one noted at interannual time scales (e.g., Annamalai et al. 2003).

An appealing result in SVD2 is the high variability explained by $h(27 \%)$ over the tropical Indian Ocean in spite of low variance in SST (19.2\%) in the Pacific. The shallower-than-normal $h$ is prominent along the coasts of Java and Sumatra and deeper-than-normal $h$ in the southwestern Indian Ocean. Consistent with SVD2, Rao et al. (2002), Huang and Kinter (2002), and Feng and Meyers (2003) note a dipole in the thermocline in the southern Indian Ocean at interannual time scales in their respective analyses of the Typhoon Operational Experiment (TOPEX) sea level anomalies, ocean model output, and repeated expendable bathythermograph (XBT) lines. By virtue of the sign of PC2 (Fig. 4b, yellow line), one can expect shallower-than-normal $h$ in the EEIO $\left(10^{\circ} \mathrm{S}-0^{\circ}, 90^{\circ}-110^{\circ} \mathrm{E}\right)$ during the 1960 s and early 1990 s by $10-15 \mathrm{~m}$ and deeper-than-normal $h$ during the 1970s and 1980s and in the late 1990s by 10-15 $\mathrm{m}$ (PCs multiplied by anomalies in the spatial patterns).

\section{2) SVD RESULTS FROM INDIAN OCEAN SSTA}

The climate shift in the mid-1970s also resulted in the warming of SST in the tropical Indian Ocean (e.g., Mi- nobe 1997; Deser et al. 2004). To examine, if the equatorial wind pattern in Fig. $3 b$ covaries with Indian Ocean decadal SST variability, we carried out another SVD analysis similar to the preceding one but with SST values confined to the tropical Indian Ocean. The SST spatial pattern of SVD1 (Fig. 5a) shows a basinwide warming with a maximum in the equatorial central Indian Ocean and northwest of Australia. The associated wind variability (Fig. 5b) is nearly identical to that shown in Fig. 2b. The SVD2 pattern of SST (Fig. 5c) shows maximum positive values in the southwest Indian Ocean centered at $30^{\circ} \mathrm{S}, 70^{\circ} \mathrm{E}$. The associated winds (Fig. 5d) do not depict easterly (westerly) anomalies along the equatorial Indian (central Pacific) ocean as in Fig. 3b.

In summary, results from the SVD analyses suggest that Pacific SST exerts considerable influence on the EEIO theromocline, either through the ITF transport (oceanic teleconnection) or through the equatorial winds over the Indian Ocean (atmospheric teleconnection). The influence of SVD2 in this process is higher suggesting a more important role of equatorial Pacific than North Pacific (SVD1) SST. In contrast, SVD results with only Indian Ocean SST indicate negligible impact on the decadal wind anomalies over the equa- 


\section{$h$ difference over the EEIO}
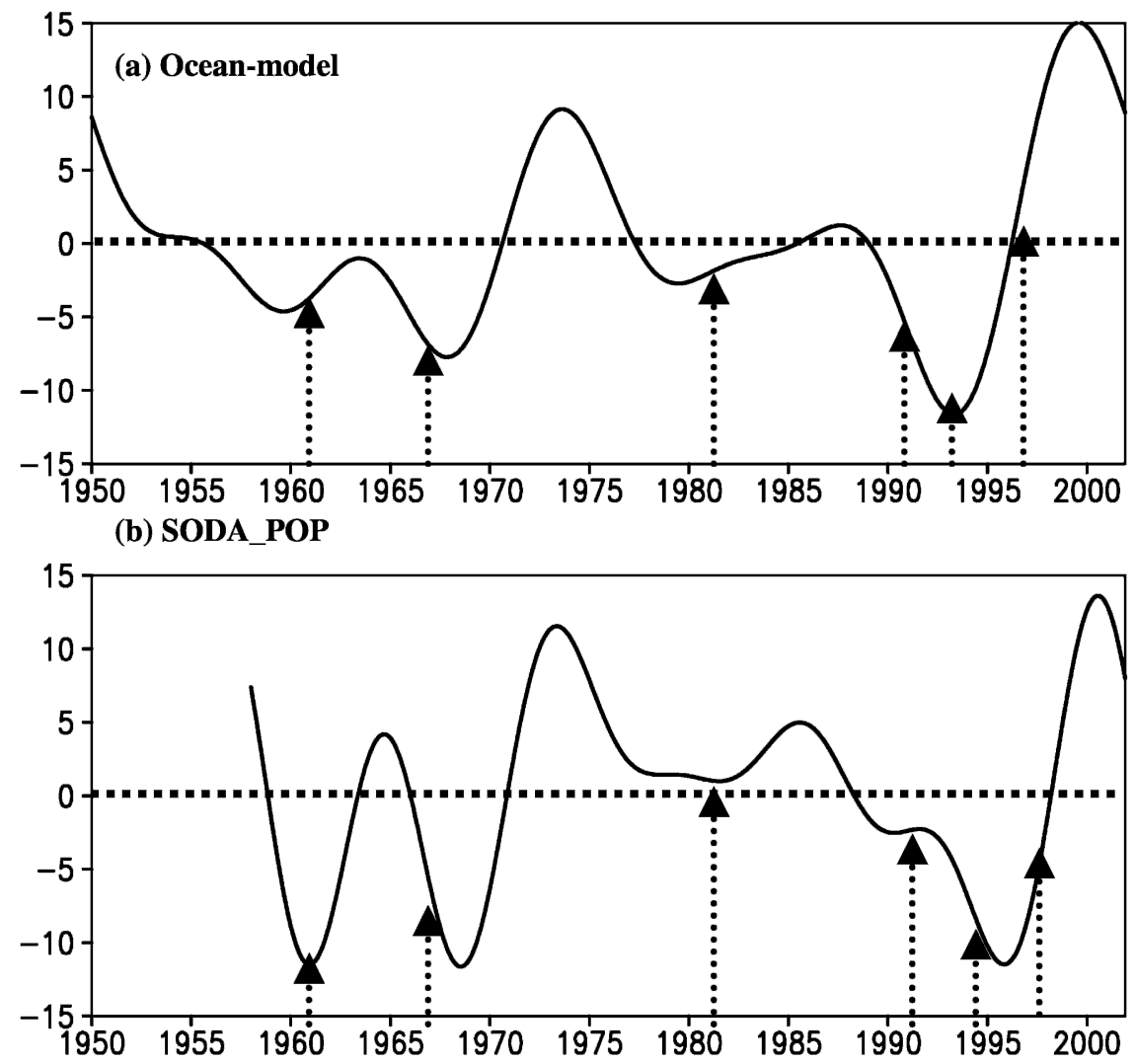

FIG. 6. Time evolution of the index $I$ representing the decadal time scale difference in $h$ over the EEIO $\left(10^{\circ} \mathrm{S}-0^{\circ}, 90^{\circ}-110^{\circ} \mathrm{E}\right.$; see text for details on how $I$ is constructed), from (a) the ocean model and (b) SODA-POP. The dotted vertical lines indicate years of strong IODZM events.

torial Indian Ocean, and we therefore infer that PDV is the primary agent for preconditioning the EEIO thermocline. We repeated SVD calculations with the two new SST products (section 2) and noted no changes to the results.

\section{b. Index of EEIO preconditioning}

A key assumption in our discussion is that IODZM events are favored only when $h$ is shallow enough in the EEIO for SST to cool below $27.5^{\circ} \mathrm{C}$, the threshold required for deep convection in the Tropics (e.g., Graham and Barnett 1987). Accordingly, we constructed a measure for EEIO preconditioning, $I$, based on $h$. Let $\Delta h 1$ and $\Delta h 2$ be the average value of anomalous $h$ in the EEIO domain determined from the SVD1 and SVD2 patterns (Figs. 2c and 3c). Then,

$$
I=\mathrm{PC} 1 \times \Delta h 1+\mathrm{PC} 2 \times \Delta h 2 .
$$

Figure 6 plots $I$, together with the occurrence of strong IODZM events. Note that strong events almost always occur in periods when $I$ is negative, that is, when $h$ is anomalously shallow in the EEIO; the exceptions are the 1997 and 1982 events that occurred when $I$ was weakly positive and negative, respectively, an indication that large El Niños can trigger IODZM events even without preconditioning. Another notable feature is that no IODZM develops during many El Niño years, a consequence of the lack of preconditioning. Conversely, many IODZM events develop in the absence of ENSO forcing, a consequence of favorable preconditioning. By virtue of the explained variance (Fig. 4c), SVD2 contribution to $I$ is higher.

To confirm the results in Fig. 6a, we repeated the SVD analysis with $h$ from SODA-POP and winds from ERA-40, retaining SST from Reynolds and Smith (1994). The index $I$ constructed from this new analysis is plotted in Fig. 6b. The close correspondence between the two results, one obtained from our ocean model forced with NCEP-NCAR winds and the other from an ocean reanalysis product forced with ERA-40 winds is encouraging. 

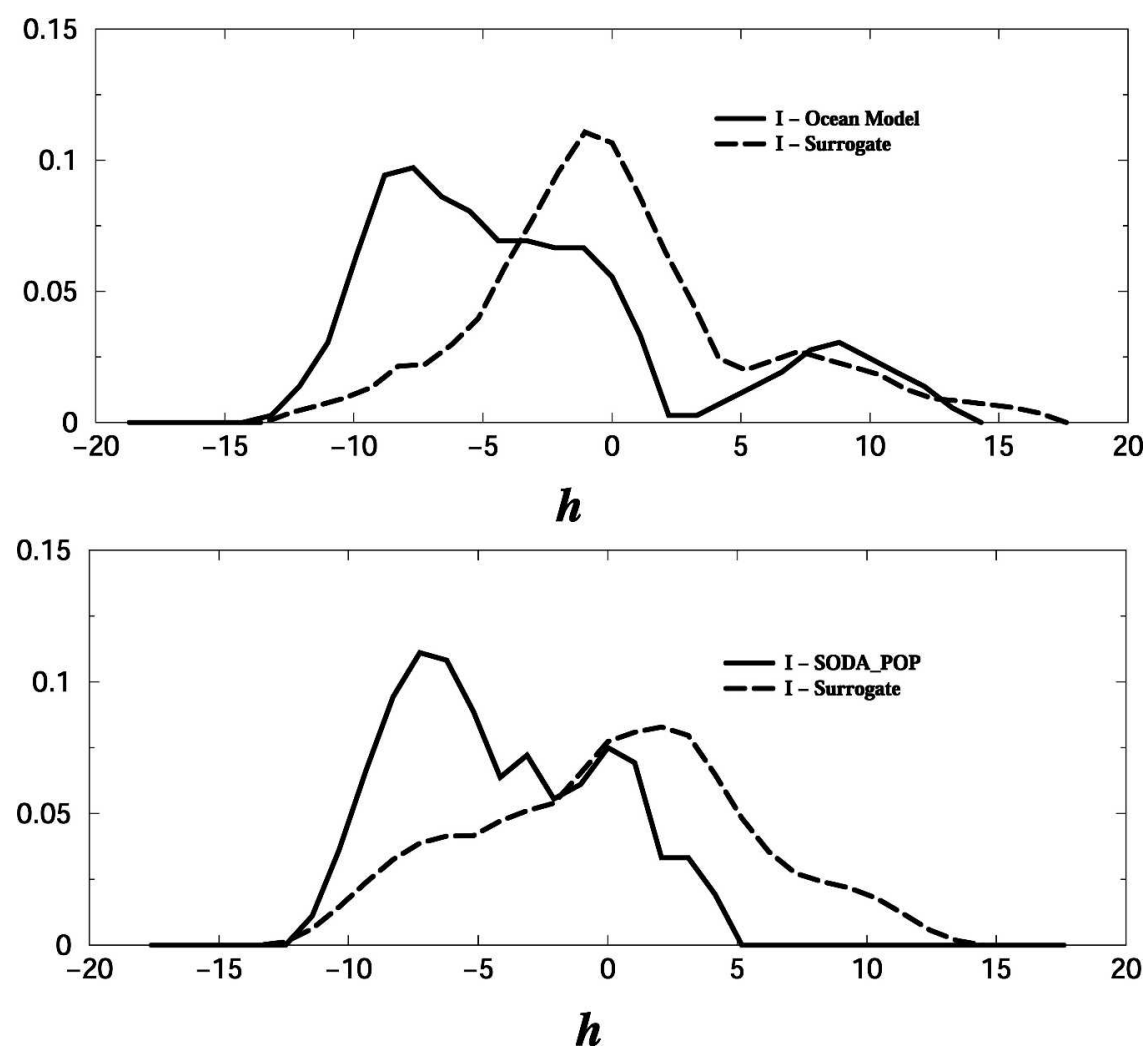

FIG. 7. The PDF of the thermocline indices shown in Fig. 6 (solid lines) and that constructed from 1000 surrogate time series (dotted line) based on the thermocline indices $(h)$ shown in Fig. 6. The PDF stratification is based on strong IODZM events. The construction of the surrogate time series is based on the algorithm of Schreiber and Schmitz (1996). The PDFs based on the surrogate time series are near-Gaussian, while those based on the thermocline indices are skewed. The difference in the mean of the PDFs is significant at the $5 \%$ level. The negative skewness in the PDFs constructed from the thermocline indices illustrates the point that the occurrence of strong IODZM is higher when the mean thermocline depth over the EEIO is lower.

To quantify the results in Fig. 6, we carried out a random occurrence test. The null hypothesis is that strong IODZM events can occur irrespective of the sign of $h$ (i.e., the shallower than normal $h$ is not a necessary condition). We constructed surrogate time series based on the method of Schreiber and Schmitz (1996). The iterative algorithm makes appropriate surrogate time series by altering the "phases" but retaining the same autocorrelations as the given data shown in Fig. 6. With this algorithm we generated 1000 surrogate time series separately for the ocean model index (Fig. 6a) and for the index derived from SODA-POP (Fig. 6b). The probability density function (PDF), a quantitative measure to test the hypothesis, is then estimated for both the thermocline indices (Fig. 6) and the surrogate time series. The PDF stratification is based upon strong IODZM events (cf. Fig. 1a). In Fig. 7 we show the PDFs obtained from the surrogate time series (dotted lines) and from the thermocline indices (solid lines). The PDFs constructed from the thermcoline indices are systematically perturbed toward negative values of $h$ while that from both the surrogate time series is nearGaussian. The difference in the means of the PDFs constructed from the thermocline indices and those from the surrogate time series is significant at $5 \%$ level, and therefore illustrate the point that the occurrence of strong IODZM events is preferred when $h$ is below normal at decadal time scales.

\section{c. Wind response from linearized model}

To strengthen our arguments that the decadal wind anomalies over the equatorial Indian Ocean are primarily forced by Pacific SST anomalies, we obtained solutions to the LBM. SST anomalies used to force the model are obtained by regressing PC2 of SST (Fig. 4b, red line) onto SST over the tropical Indo-Pacific region 
(a)

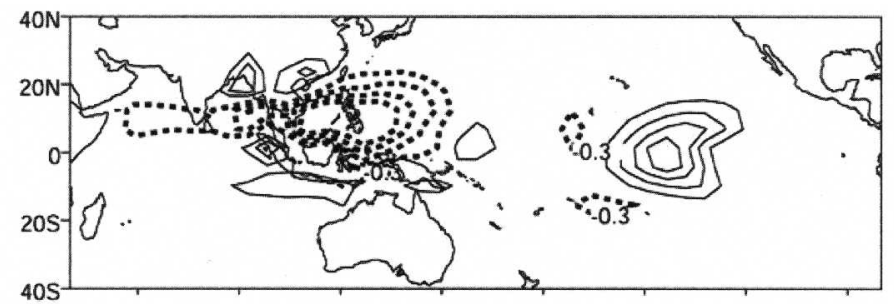

(b)

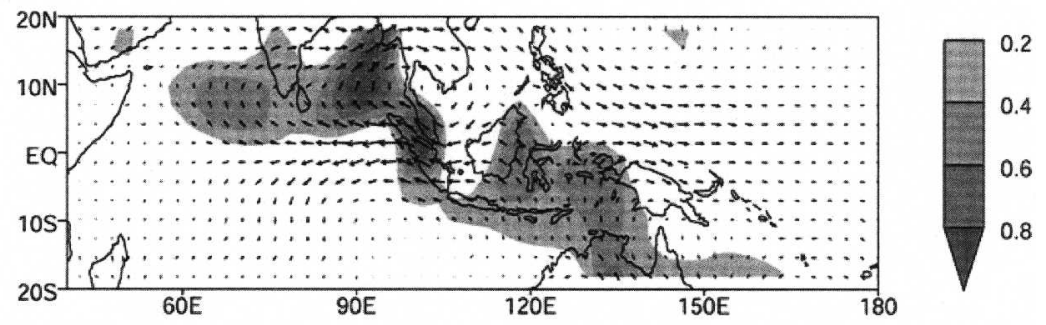

(c)

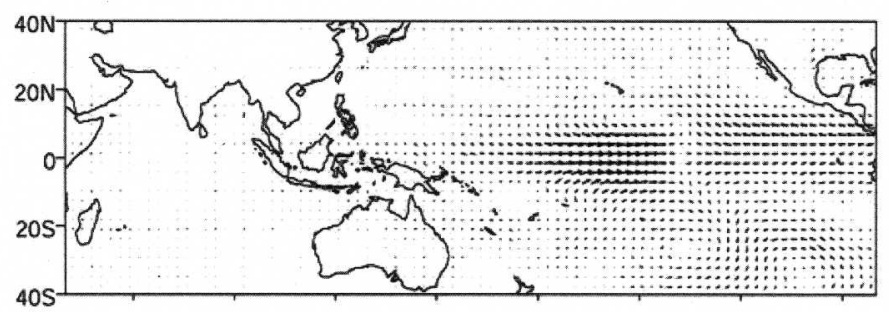

(d)

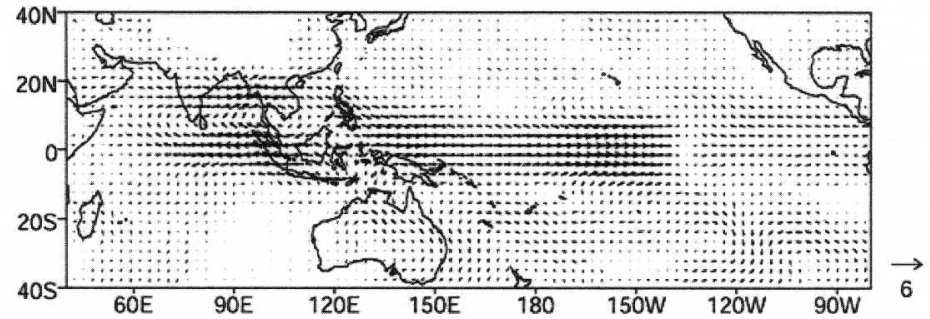

FIG. 8. (a) LBM-generated column-integrated heating $\left(\mathrm{K} \mathrm{day}^{-1}\right)$ due to cold (warm) SST anomalies over the western (central) Pacific associated with SVD2 of SST shown in Fig. 3a. The center of the maximum SST anomalies $\left(1.0^{\circ} \mathrm{C}\right)$ is placed at $0^{\circ}, 135^{\circ} \mathrm{E}$ for the cold case and at $0^{\circ}, 150^{\circ} \mathrm{W}$ for the warm case. The zonal and meridional extent of the prescribed SST anomalies is $20^{\circ}$ and $10^{\circ}$, respectively, in both cases. (b) The steady-state response wind anomalies at $850 \mathrm{hPa}$ to the cold case; (c) same as (b) but for the warm case; and (d) their sum. Note that in (b) the wind anomalies are shown for a limited region and the positive values of the meridional component are also shaded to highlight the upwelling-favorable winds off Sumatra-Java.

(not shown). Apart from retaining the spatial pattern shown in Fig. 3a, cold SST anomalies over the southeastern tropical Indian Ocean (as noted in Fig. 5c) are also apparent in the regression analysis. To understand the individual and collective roles of SST anomalies in various regions on the wind patterns, we carried out four experiments with SST patterns over (i) southeastern tropical Indian Ocean, (ii) tropical western Pacific, (iii) equatorial central Pacific, and (iv) the nearequatorial eastern Pacific. Of the four experiments, the response to both southeastern tropical Indian Ocean and near-equatorial eastern Pacific SST forcing was very weak and localized. Therefore, we present and discuss the response to other two cases whose combined effect (Fig. 8d) resembles the observed flow pattern (Fig. 3b). The location of the maximum amplitude of the prescribed SST anomalies $\left(\sim 1.0^{\circ} \mathrm{C}\right)$ and their longitudinal and latitudinal extent are provided in Fig. 8.

Figure 8a shows the spatial pattern of the columnintegrated heating $\left(\mathrm{K} \mathrm{day}^{-1}\right)$ generated by the model. The $850-\mathrm{hPa}$ wind response to negative (positive) heat- 
ing over the western (equatorial central) Pacific is shown in Fig. 8b (Fig. 8c). The Kelvin wave response to western Pacific heating generates westerly anomalies in the equatorial central Pacific that are symmetric about the equator. An anticyclonic circulation develops west of the heating anomalies as a Rossby wave response causing easterly anomalies along the equatorial Indian Ocean. The shading in Fig. 8b highlights the upwellingfavorable winds off Sumatra (only positive values of the meridional component of the wind are shaded) and the LBM solutions qualitatively agree with Fig. $3 b$. The response to central Pacific positive SST anomalies is felt over the equatorial Pacific with a weak signature over the equatorial Indian Ocean.

In a recent ongoing work, it is found that the area covered by the western Pacific warm pool waxes and wanes at decadal time scales (V. Mehta 2002, personal communication). Consistent with that variability, the SVD2 SST pattern (Fig. 3a) captures a considerable signal over the western Pacific warm pool. The decadal persistence of SST anomalies over the warm pool, despite being small in magnitude $\left(\sim 0.3^{\circ}-0.5^{\circ} \mathrm{C}\right.$ in certain decades like the 1960s and 1990s), may allow them to have an appreciable influence on local convection and subsequently on the low-level winds, as shown by the LBM experiments.

\section{d. Influence of decadal wind anomalies in the EEIO}

To demonstrate that it is the winds in the equatorial Indian Ocean that affect the background $h$ over the EEIO, we forced the ocean model with two idealized, zonal wind stress anomalies confined to the region $10^{\circ} \mathrm{S}-10^{\circ} \mathrm{N}, 50^{\circ}-110^{\circ} \mathrm{E}$; their strengths are uniformly \pm 0.15 dynes $\mathrm{cm}^{-2}$ throughout the region, consistent with the values of the observed anomalies in Fig. $3 b$. The two runs are labeled EAST and WEST for easterly and westerly anomalies, respectively (Table 1 ). Figure 9a shows the $h$ differences for the EAST-WEST solution during May-August. As expected, $h$ shallows throughout the EEIO, particularly off the Sumatran coast. Figures 9b,c show depth-time temperature profiles averaged over the EEIO region for the EAST and WEST runs. During all months, $h$ as indicated by the depth of the $24^{\circ} \mathrm{C}$ isotherm is shallower in EAST in comparison to WEST, a consequence of the greater upward tilt of the equatorial thermocline to the east in EAST in response to the equatorial easterlies. Consequently, when EEIO seasonal upwelling is initiated, colder water is upwelled to the surface in EAST than in WEST.

Despite a small contribution from the SVD1/PC1 on $h$, our focus has been mainly on understanding the ex- (a)

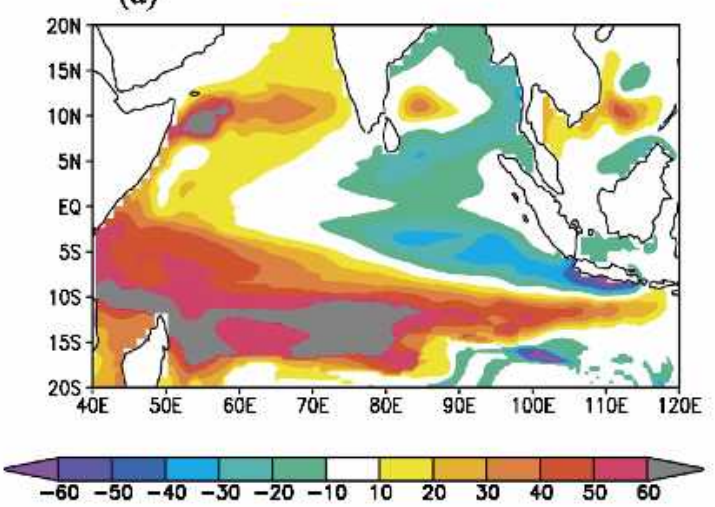

(b)

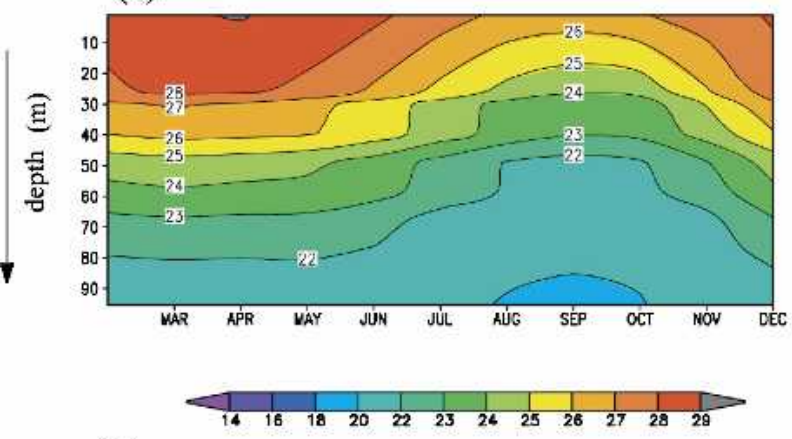

(c)

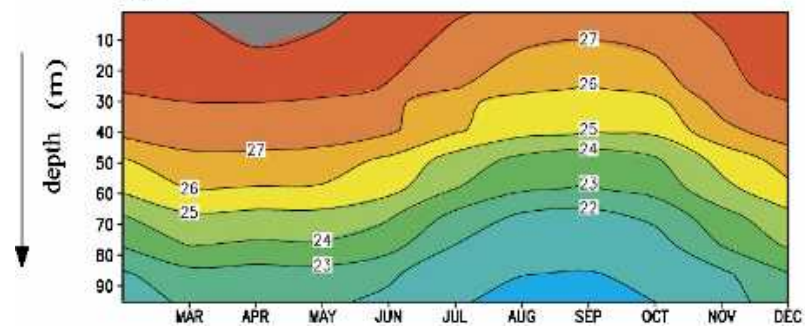

FIG. 9. (a) The $24^{\circ} \mathrm{C}$ isotherm difference (m) between EAST and WEST runs and averaged over May-Aug; (b) depth vs temperature $\left({ }^{\circ} \mathrm{C}\right)$ over EEIO for EAST run shown as a function of time; and (c) same as (b) but for the WEST run.

clusive effect of SVD2/PC2 on EEIO preconditioning. Specifically, we have concentrated on understanding the possible causes for the wind patterns over the equatorial Indian Ocean (section 3c) and their effect on EEIO preconditioning. To determine the influence of realistic wind anomalies, we also forced the ocean model with winds obtained from decadal time-mean differences that have both the Pacific and Indian Ocean components (not shown). For example, the ocean model forced with wind stress differences between the 1990s and 1970s and the 1960s and 1970s yielded similar changes to those shown in Fig. 8 on the EEIO thermocline (not shown). The only differences were in the ITF transport that was reduced in the 1990s-70s run but 
(a)

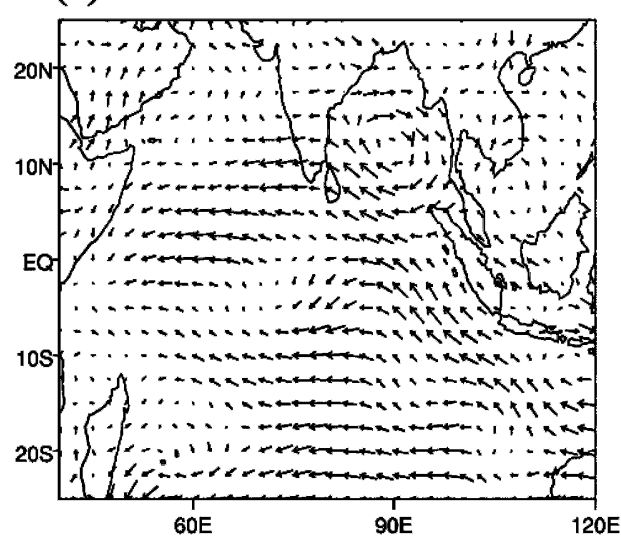

(c)
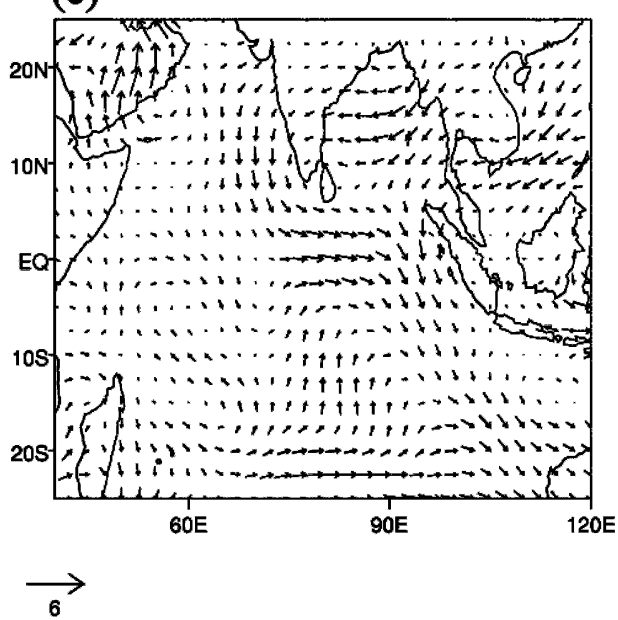

(b)

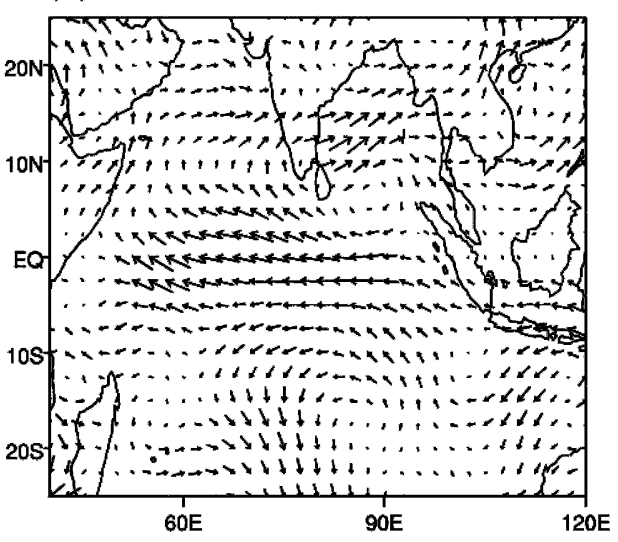

$\overrightarrow{6}$

(d)

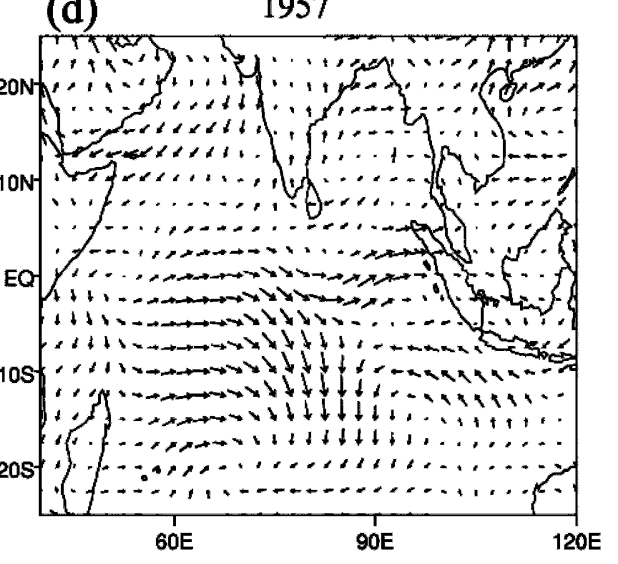

$\overrightarrow{6}$

FIG. 10. Observed surface wind anomalies $\left(\mathrm{m} \mathrm{s}^{-1}\right)$ averaged during May-Jun for (a) 1997, (b) 1961,

(c) 1996, and (d) 1957. The reference wind vector is also shown.

increased in the 1960s-70s run, and in changes to the thermocline off south Java.

\section{Effect of preconditioning on IODZM events}

In this section, we discuss how IODZM events are influenced by EEIO preconditioning and by wind anomalies during their onset stage in May-June (section 4a). Then, the results of the present study are interpreted regarding the observed status of Indian Ocean SST anomalies during the years of 2002-03 (section 4b).

\section{a. Case studies}

We carried out a suite of sensitivity experiments to investigate the role of wind anomalies during the IODZM event onset stage (May-June). All the experi- ments are initialized (preconditioned) with output from the final year of either the EAST, WEST, or CTL runs. They are then forced with additional wind stress anomaly fields from particular years (Fig. 10). The model runs begin in April, just before the triggering stage of IODZM events (Annamalai et al. 2003). The selected years are the following: 1997, which had both a strong El Niño and a IODZM event; 1961, which had a strong IODZM event but near-normal conditions in the eastern equatorial Pacific (e.g., Saji et al. 1999); 1996, which had no IODZM event but La Niña; and 1957, an El Niño year but with no IODZM event. The model run initialized with the EAST run and subsequently forced by 1997 winds is labeled EAST97, and other runs are analogously designated (WEST97, EAST57, etc.).

Based on the observational fact that SST greater than $27.5^{\circ} \mathrm{C}$ is a necessary condition for the occurrence of deep convection in the Tropics (e.g., Graham and Bar- 
(a)

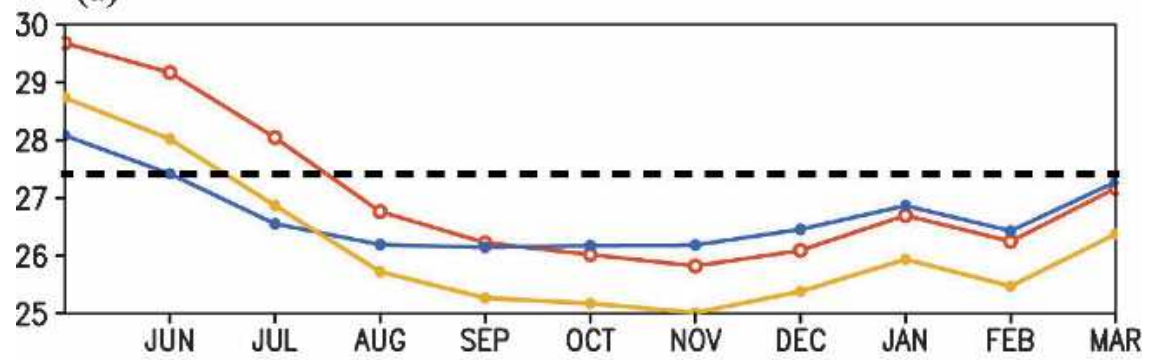

(b)

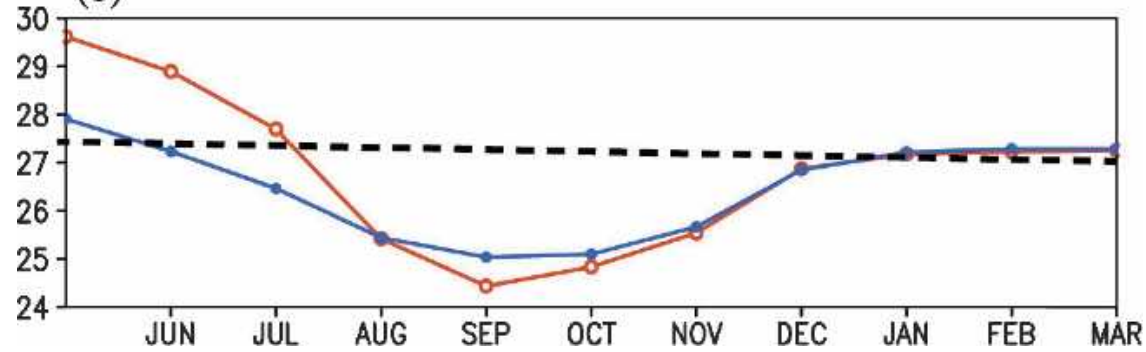

FIG. 11. Evolution of SST over the EEIO: (a) EAST97 (blue), CLIM97 (yellow), and WEST97 (red); (b) EAST61 (blue) and WEST61 (red). The $27.5^{\circ} \mathrm{C}$ threshold required for deep convection to occur in the Tropics is shown as dotted line.

nett 1987), we examine the monthly evolution of mixed-layer temperature or SST from the model experiments. If SST over the EEIO drops below $27.5^{\circ} \mathrm{C}$, we assume that local convection is suppressed resulting in changes in low-level wind patterns, then, the positive feedback between atmosphere and ocean results in the development of IODZM.

\section{1) 1997 WINDS}

Figure 11a shows the monthly evolution of SST in the EEIO for both solutions. In EAST97 (blue curve), SST cools rapidly after the upwelling-favorable, equatorial and coastal winds are switched on, and by June it becomes less than $27.5^{\circ} \mathrm{C}$. In contrast, SST in WEST97 (red curve) does not become less than $27.5^{\circ} \mathrm{C}$ until midJuly. As indicated in Fig. 6, $h$ is near normal during 1997, another experiment was run using 1997 winds, and an initial ocean condition provided by the climatological run (CTL97). This experiment was designed to address the question that very strong ENSO forcing could trigger an IODZM event in the absence of preconditioning. The SST evolution (Fig. 11a, yellow curve) supports this idea, and strong IODZM events in 1982 and 1997 are possibly due to strong ENSO forcing. The cooling is, however, stronger in CTL97 than in EAST97 run, and is attributed to higher ITF transport in the latter due to additional easterly winds. As a consequence, the thermocline off south Java deepens resulting in the warming of SST there.
The depth-time temperature profiles for EAST97 and WEST97 (Fig. 12) illustrate that the SST difference between the two solutions occurs in association with changes in the deeper thermal structure. The nearsurface temperatures are cooler in EAST97 compared to those in WEST97. As a result, SST cools immediately in EAST97 as the upwelling-favorable winds increase during the summer, whereas in WEST97 water with temperature less than $27^{\circ} \mathrm{C}$ is not lifted to the depth of the mixed layer $(30 \mathrm{~m})$ until August. (An analysis of the mixed-layer heat budget confirms that upwelling-forced entrainment into the mixed layer is the dominant cooling process during the summer.) As expected from forced runs, SST evolutions in both the solutions converge thereafter (Fig. 11a).

Two aspects of the wind forcing contribute to this upwelling: anomalously strong, upwelling-favorable winds along the equator and the coast of Sumatra. In addition, the propagation of Rossby waves from the Sumatran coast also helps to raise the thermocline in the EEIO after some time delay (2-4 months).

\section{2) 1961 WINDS}

Figure 11b shows the SST evolution for EAST61 (blue curve) and WEST61 (red curve) solutions. As in EAST97, SST cools rapidly in EAST61 than in WEST61. This is a clear example that an IODZM can develop when near-normal conditions exist in the eastern equatorial Pacific. 


\section{(a)}
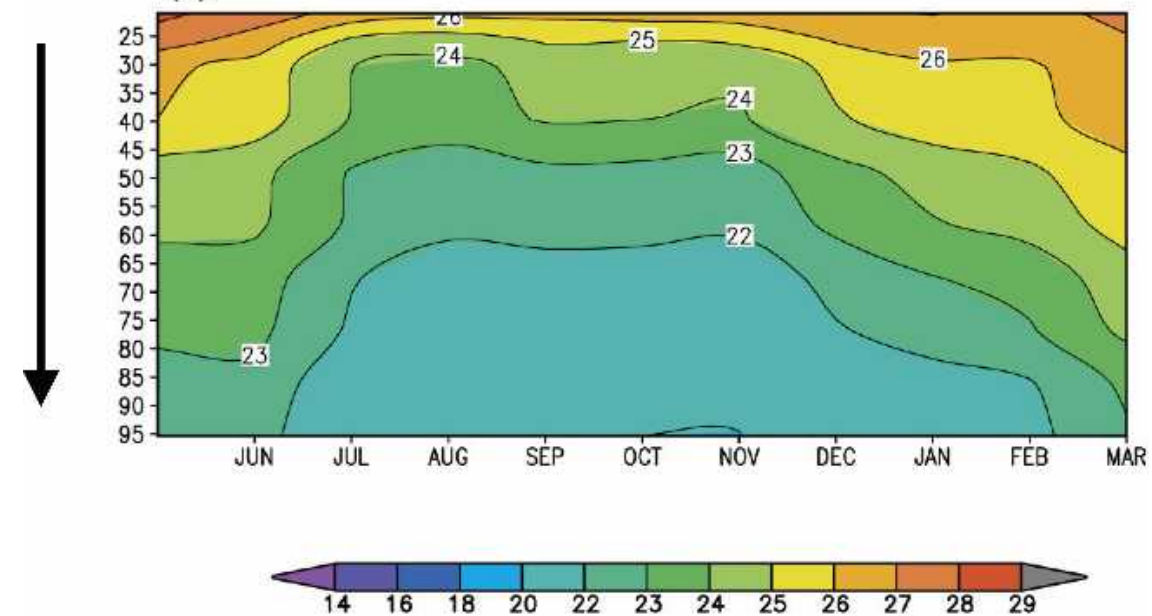

(b)

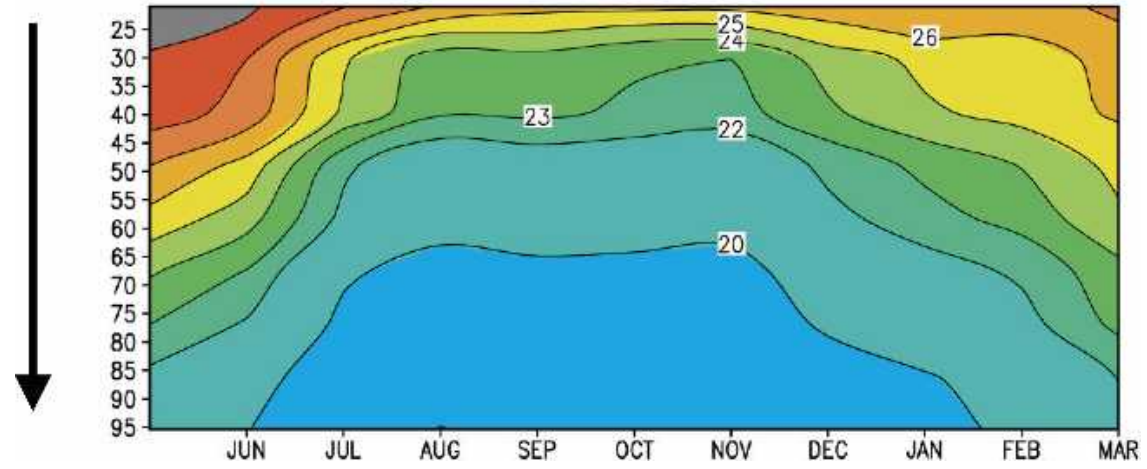

FIG. 12. Depth vs temperature $\left({ }^{\circ} \mathrm{C}\right)$ over the EEIO for (a) EAST97 and (b) WEST97 runs, shown as a function of time.

\section{3) 1996 WINDS}

In EAST96 and WEST96 (Fig. 13a), SST does not cool below $27.5^{\circ} \mathrm{C}$ at any time in the EEIO, a consequence of equatorial westerly anomalies during the spring/early summer of 1996 deepening the EEIO thermocline. Thus, even when the EEIO is preconditioned, the presence of westerly wind anomalies due to La Niña conditions is sufficient to inhibit an IODZM event.

\section{4) 1957 WINDS}

The year 1957 is noteworthy in that the thermocline was weakly shallow in the EEIO (Fig. 6) and there was also an ENSO; yet there were relatively weak equatorial and Sumatran winds (Fig. 10d). In EAST57 (Fig. 13b, blue curve), cooling during the first 3 months (May-July) is only of the order of $0.5^{\circ} \mathrm{C}$, considerably less than the $1.5^{\circ} \mathrm{C}$ drop in EAST97 (Fig. 11a), a clear indication of the influence of the intensity of the additional forcing (Fig. 10d). So, even though there is sur- face cooling in boreal fall due to wind-driven fluxes, as is the case for many El Niño years (e.g., Krishnamurthy and Kirtman 2003), it is weak. Thus, the intensity and timing of the external forcing, as well as preconditioning, modulates EEIO SST evolution and IODZM events development. In summary, the difference between all EAST and WEST experiments is merely the timing of the appearance of the $27.5^{\circ} \mathrm{C}$ isotherm to perturb the overlying atmospheric precipitation.

\section{b. Status of the Indian Ocean during 2002-03}

Since 1999 the phase of PDV has changed, and consistent with our hypothesis, the mean EEIO thermocline was 10-15 m deeper than normal in 2002 (Fig. 6) when a moderate El Niño developed in the Pacific. As in previous cases, no IODZM event developed in 2002 due to a lack of preconditioning. It should be mentioned here that the change in $h$ between early to late 1990s is about 25-30 m (Fig. 6). On the other hand, the summer of 2003 witnessed a weak IODZM event 
(a)

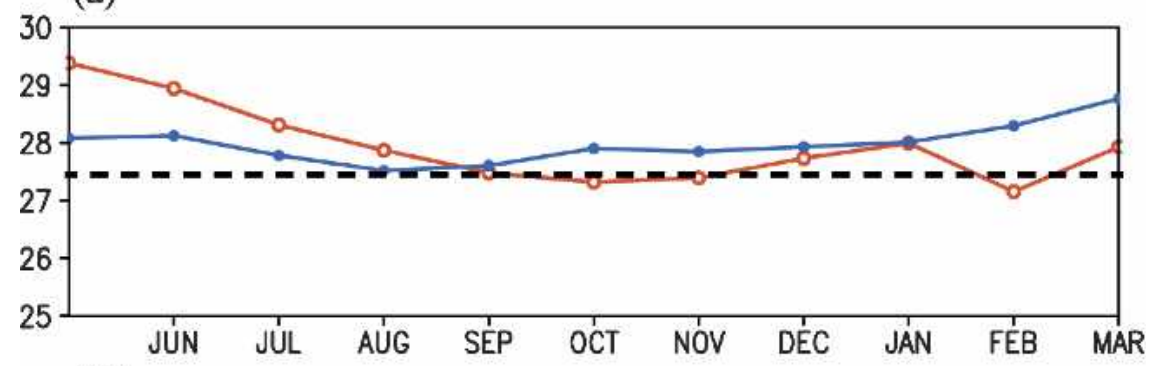

(b)

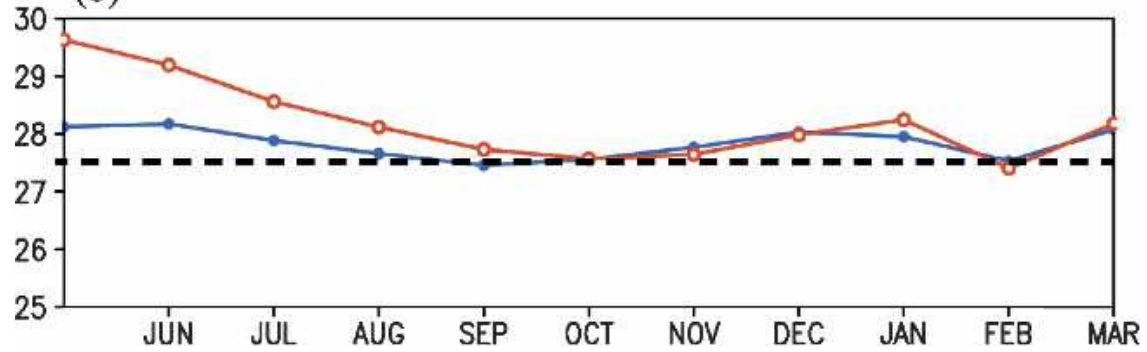

FIG. 13. Same as in Fig. 11 but for (a) EAST96 (blue) and WEST96 (red) and (b) EAST57 (blue) and WEST57 (red). The $27.5^{\circ} \mathrm{C}$ threshold required for deep convection to occur in the Tropics is shown as dotted line.

(Fig. 14). The anomalous SST evolution over the EEIO during 2003 (Fig. 14c) shows that the cooling during June-July is accompanied by weakened convection and anomalous equatorial easterlies over the Indian Ocean (Fig. 14a). In sharp contrast, $h$ over the EEIO is deeper than normal in August (Fig. 14d). As a result, the cooling vanished by mid-August (Fig. 14c) and anomalous convection strengthened over the EEIO (Fig. 14b) terminating the development of the IODZM event. A mixed-layer heat budget analysis for 2003 (not shown) indicates that SST cooling was primarily due to winddriven fluxes with little contribution from the entrainment term.

\section{Discussion and summary}

In the present study, we explore the hypothesis that PDV is an important factor in determining the occurrence of strong IODZM events in the 1960s and 1990s, through both atmospheric teleconnections to the Indian Ocean equatorial wind field and oceanic teleconnections via the Indonesian Throughflow. In the present study, however, more focus has been paid to the role of the atmospheric teleconnection.

To identify the influence of PDV in the Indo-Pacific domain, we performed SVD analysis on low-passfiltered data (section 3a). The SST pattern of SVD1 captures the traditional PDV pattern, and the surface winds show weakening of the easterly trade winds in the Pacific, implying El Niño-like conditions. The $h$ anomalies in the Indian Ocean are shallower than normal off south Java (Fig. 2c). The strong phase relationship between PC1 of $h$ (Fig. 4a) and the 8-yr running mean of ITF (Fig. 4c) indicates that SVD1 influences the EEIO thermocline primarily due to a reduction in the ITF transport. The PC1 of all these variables capture the major climate shift of 1976-77. We note that SVD1 contribution to the overall EEIO thermocline preconditioning is rather small.

The SVD2 patterns are new findings of the present study (Fig. 3). The SST pattern of SVD2 captures the cooling (warming) over the western (central) Pacific during 1952-71 and 1989-96. The associated surface wind variability captures easterly wind anomalies over the equatorial Indian Ocean together with anticyclonic circulation anomalies in the southeastern Indian Ocean. The known oceanic response to this wind patch is to shoal the EEIO thermocline (Fig. 3c). Collectively, SVD1 and SVD2 are referred to as PDV in the present study. A separate SVD analysis with Indian Ocean SST reveals negligible impact on EEIO thermocline (Fig. 5).

Based upon the two PCs we define an index, $I$, that measures $h$ in the EEIO (section 3b). Consistent with the hypothesis, $I$ indicates shallower-than-normal $h$ during 1958-69 and 1990-96 (Fig. 6). This hypothesis allows for the growth of a coupled mode in the EEIO in the absence of ENSO forcing given appropriate preconditioning of the thermocline. Such preconditioning 
(a) OLR anomalies (June-July)
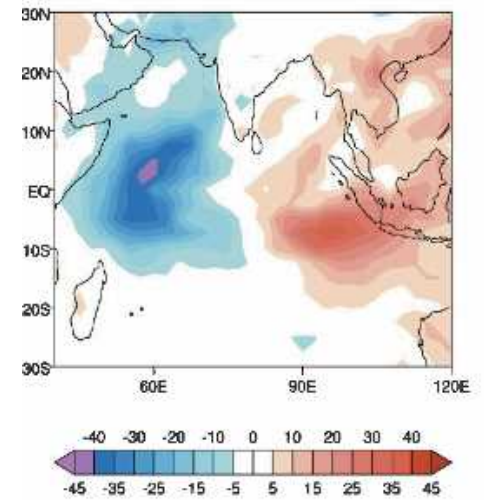

(b) OLR anomalies (Aug-Sept)
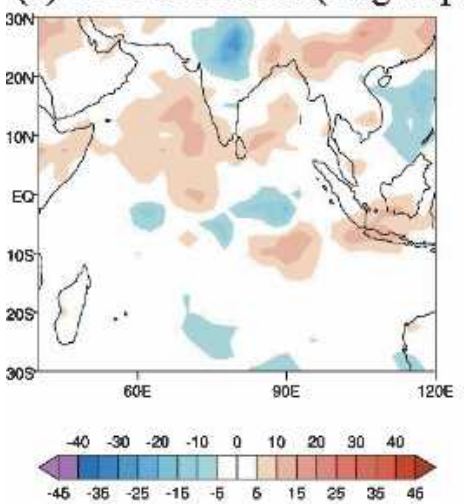

\section{(c) EEIO - SST anomalies}

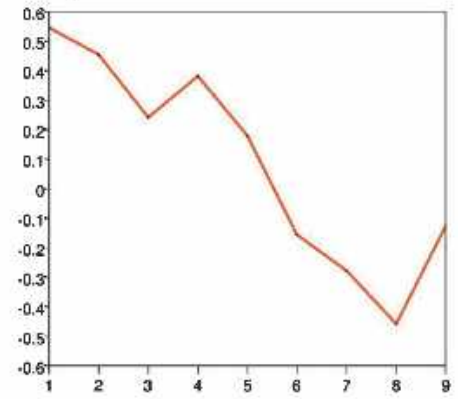

Month starting from January

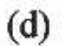

(d)

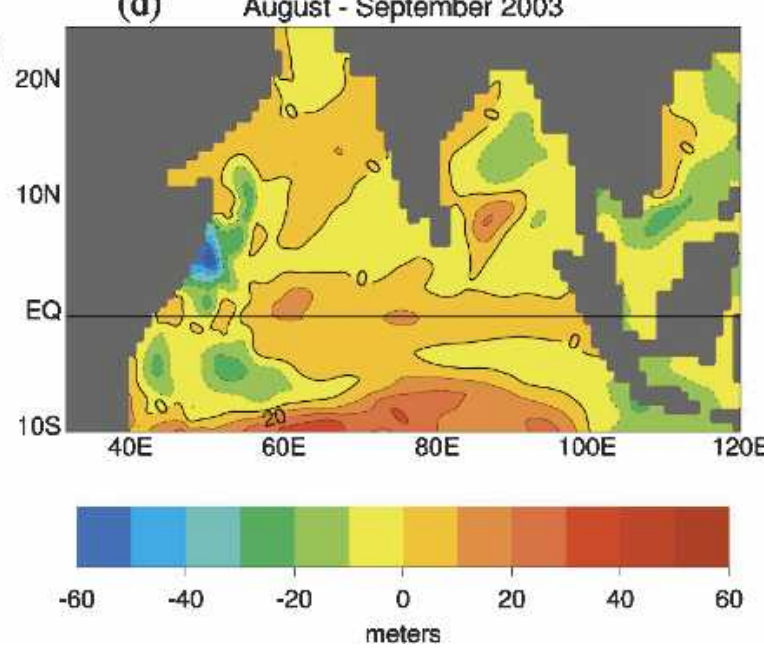

FIG. 14. Bimonthly averaged observed OLR anomalies $\left(\mathrm{W} \mathrm{m}^{-2}\right)$ for 2003: (a) Jun-Jul and (b) AugSep, and (d) $h$ anomalies during Aug-Sep 2003. (c) The monthly evolution of SST anomalies $\left({ }^{\circ} \mathrm{C}\right)$ from Reynolds averaged over the EEIO for 2003.

is important because, in contrast to the eastern Pacific, the annual-mean $h$ is typically too deep in the EEIO to allow significant upwelling of cool water. Barnett et al. (1999) asserted that the low-frequency variability in the North Pacific preconditions ENSO conditions in the equatorial Pacific. Our results indicate that PDV also influences EEIO.

Our results suggest the following scenario for linking the SVD2 pattern to EEIO: Persistently warm SST anomalies in the equatorial central Pacific and cold SST anomalies in the western Pacific shift convection eastward from the Maritime Continent, thereby weakening the Pacific Walker circulation and causing anomalous subsidence over the EEIO Maritime Continent; forced by this heat sink, a low-level anticyclone develops in the EEIO as a Rossby wave response along with easterly wind anomalies over the equatorial Indian Ocean (Figs. $3 \mathrm{~b}$ and $8 \mathrm{~b}$ ). In an earlier study, Annamalai et al. (2003) showed that at interannual time scales SST anomalies over the equatorial Pacific near $160^{\circ} \mathrm{E}$ during boreal spring are important for triggering an IODZM event. In contrast, at decadal time scales SST anomalies over the central Pacific near $160^{\circ} \mathrm{W}$ and western Pacific near $130^{\circ} \mathrm{E}$ appear to be important for EEIO thermocline preconditioning. Solutions from a linear simple atmospheric model forced with SVD2 SST anomalies confirm the role of Pacific SST in forcing the equatorial winds in the Indian Ocean.

In addition, through a suite of ocean model experiments forced by idealized (EAST and WEST) wind anomalies, and additional model runs forced by observed winds from individual years (section $4 \mathrm{~b}$; Table 1 ) we studied the effect of preconditioning and external trigger in the development of IODZM. In the experiments when $h$ is preconditioned to be shallower than normal, such trigger events allow SST in the EEIO to cool below $27.5^{\circ} \mathrm{C}$ more rapidly due to the entrainment of cooler subsurface water. In a coupled scenario, this earlier drop in SST can suppress in situ convection during May-June, generating positive feedback between 
the ocean and atmosphere that can lead to a strong IODZM event. Conversely, an IODZM event does not develop when $h$ is anomalously deep. The proposed conceptual picture is evident during the evolution of a weak IODZM event that occurred in the summer of 2003. In summary, the difference between all EAST and WEST experiments is merely the timing of the appearance of the $27.5^{\circ} \mathrm{C}$ isotherm to perturb the overlying atmospheric precipitation.

In conclusion, we have presented evidence indicating that a shallow thermocline in the EEIO is a necessary precondition for strong IODZM activity. However, there are caveats that temper our results. First, the regions off Java and Sumatra are data void, and therefore the SST analysis prior to the satellite era is debatable. Sustained observational efforts, by both in situ and space-borne sensors, are necessary to confirm the preferred occurrence of strong IODZM events in certain decades. Second, our supporting numerical experiment utilizes an ocean model forced by observed winds, whereas the winds themselves are end products of coupled ocean-atmosphere processes. Our hypothesis, then, remains to be confirmed in a coupled model that internally develops its own winds, and efforts are currently under way to achieve this goal.

Acknowledgments. The authors thank Dr. Niklas Schneider for fruitful discussions and for comments on an earlier version of the manuscript. Dr. Axel Timmermann is thanked for suggesting the statistical significance test used to prepare Fig. 7. This research was supported by the Japan Agency for Marine-Earth Science and Technology (JAMSTEC) through its sponsorship of the International Pacific Research Center. R. Murtugudde acknowledges NASA Indian Ocean Biogeochemistry, ISO, Salinity, and TRMM grants for partial support during this work. Partial support from the NOAA/OGP/Pacific program is also acknowledged. The comments and critics from the anonymous reviewers are greatly appreciated.

\section{REFERENCES}

Alan, R. J., and Coauthors, 2001: Is there an Indian Ocean dipole, and is it independent of the El Niño-Southern Oscillations? CLIVAR Exchanges, Vol. 6, No. 3, 18-22.

Annamalai, H., J. M. Slingo, K. R. Sperber, and K. Hodges, 1999: The mean evolution and variability of the Asian summer monsoon: Comparison of ECMWF and NCEP-NCAR reanalyses. Mon. Wea. Rev., 127, 1157-1186.

— , R. Murtugudde, J. Potemra, S. P. Xie, P. Liu, and B. Wang, 2003: Coupled dynamics in the Indian Ocean: Spring initiation of the zonal mode. Deep-Sea Res., 50B, 2305-2330.

Barnett, T. P., D. W. Pierce, M. Latif, D. Dommenget, and R. Saravanan, 1999: Interdecadal interactions between the trop- ics and midlatitudes in the Pacific basin. Geophys. Res. Lett., 26, 615-619.

Behera, S. K., R. Krishnan, and T. Yamagata, 1999: Unusual ocean-atmosphere conditions in the tropical Indian Ocean during 1994. Geophys. Res. Lett., 26, 3001-3004.

Betts, A., and M. J. Miller, 1986: A new convective adjustment scheme. Part II: Single column tests using GATE wave, BOMEX, ATEX, and artic air-mass data sets. Quart. J. Roy. Meteor. Soc., 112, 693-709.

Bjerknes, J., 1969: Atmospheric teleconnections from the equatorial Pacific. Mon. Wea. Rev., 97, 163-172.

Bretherton, C. S., A. Smith, and J. M. Wallace, 1992: An intercomparison of methods for finding coupled patterns in climate data. J. Climate, 5, 541-560.

Chen, D., L. M. Rothstein, and A. J. Busalacchi, 1994: A hybrid vertical mixing scheme and its application to tropical ocean models. J. Phys. Oceanogr., 24, 2156-2179.

Deser, C., A. S. Phillips, and J. W. Hurrell, 2004: Pacific interdecadal climate variability: Linkages between the Tropics and the North Pacific during boreal winter since 1900. J. Climate, 17, 3109-3124.

Feng, M., and G. Meyers, 2003: Interannual variability in the tropical Indian Ocean: A two-year time-scale of the Indian Ocean Dipole. Deep-Sea Res., 50B, 2263-2284.

Graham, N. E., and T. P. Barnett, 1987: Sea surface temperature, surface wind divergence, and convection over tropical oceans. Science, 258, 657-659.

Gill, A. E., 1980: Some simple solutions for heat induced tropical circulation. Quart. J. Roy. Meteor. Soc., 106, 447-462.

Hackert, E., A. J. Busalacchi, and R. Murtugudde, 2001: A wind comparison study using an ocean general circulation model for the 1997-98 El Niño. J. Geophys. Res., 106, 2345-2362.

Hare, S. R., and N. J. Mantua, 2000: Empirical evidence for North Pacific regime shifts in 1977 and 1989. Progress in Oceanography, Vol. 47, Pergamon, 103-145.

Hastenrath, S., 2002: Dipoles, temperature gradients, and tropical climate anomalies. Bull. Amer. Meteor. Soc., 83, 735-738.

Huang, B., and J. L. Kinter, 2002: The interannual variability in the tropical Indian Ocean and its relations to El NiñoSouthern Oscillation. J. Geophys. Res., 107, 3199, doi:10.1029/2001JC001278.

Kalnay, E., and Coauthors, 1996: The NCEP/NCAR 40-Year Reanalysis Project. Bull. Amer. Meteor. Soc., 77, 437-471.

Kinter, J. L., M. J. Fennessy, V. Krishnamurthy, and L. Marx, 2004: An evaluation of the apparent interdecadal shift in the tropical divergent circulation in the NCEP-NCAR reanalysis. J. Climate, 17, 349-361.

Krishnamurthy, V., and B. Kirtman, 2003: Variability of the Indian Ocean: Relation to monsoon and ENSO. Quart. J. Roy. Meteor. Soc., 129, 1623-1646.

Latif, M., and T. Barnett, 1994: Causes of decadal variability over the North Pacific and North America. Science, 266, 634-637.

Levitus, S., and T. Boyer, 1994: Temperature. Vol. 4, World Ocean Atlas 1994, NOAA Atlas NESDIS 4, 117 pp.

McPhaden, M., and D. Zhang, 2004: Pacific Ocean circulation rebounds. Geophys. Res. Lett., 31, L18301, doi:10.1029/ 2004GL020727.

Meyers, G., 1996: Variation of Indonesian throughflow and the El Niño-Southern Oscillation. J. Geophys. Res., 101, 12255 12263.

Minobe, S., 1997: A 50-70 year climatic oscillation over the North Pacific and North America. Geophys. Res. Lett., 24, 683-686. Murtugudde, R., and A. J. Busalacchi, 1999: Interannual variabil- 
ity of the dynamics and thermodynamics of the tropical Indian Ocean. J. Climate, 12, 2300-2326.

- _ — , and J. Beauchamp, 1998a: Seasonal to interannual effects of the Indonesian Throughflow on the tropical IndoPacific basin. J. Geophys. Res., 103, 21 425-21 441.

— , B. N. Goswami, and A. J. Busalacchi, 1998b: Air-sea interaction in the southern tropical Indian Ocean and its relations to interannual variability of the monsoon over India. Proc. Int. Conf. on Monsoon and Hydrologic Cycle, Kyongju, Korea, Korean Meteorological Agency, 184-188.

— J. P. McCreary, and A. J. Busalacchi, 2000: Oceanic processes associated with anomalous events in the Indian Ocean with relevance to 1997-1998. J. Geophys. Res., 105, 32953306.

Nakamura, H., and T. Yamagata, 1999: Recent decadal SST variability in the Northwestern Pacific and associated atmospheric anomalies. Beyond El Niño: Decadal and Interdecadal Variability, A. Navarra, Ed., Springer, 49-72.

— , G. Lin, and T. Yamagata, 1997: Decadal climate variability in the North Pacific during recent decades. Bull. Amer. Meteor. Soc., 78, 2215-2225.

Nitta, T., and S. Yamada, 1989: Recent warming of tropical sea surface temperature and its relationship to the Northern Hemisphere circulation. J. Meteor. Soc. Japan, 67, 375-383.

Pierce, D. W., T. P. Barnett, and M. Latif, 2000: Connection between the Pacific Ocean Tropics and midlatitudes on decadal time scales. J. Climate, 13, 1173-1194.

Potemra, J. T., S. L. Hautala, J. Sprintall, and W. Pandoe, 2003: Vertical structure of Indonesian throughflow in a large-scale model. Deep-Sea Res., 50, 2143-2162.

Rao, S. A., S. K. Behera, Y. Masumoto, and T. Yamagata, 2002: Interannual subsurface variability in the tropical Indian Ocean with a special emphasis on the Indian Ocean dipole. Deep Sea Res., 49B, 1549-1572.

Rayner, N. A., D. E. Parker, E. B. Horton, C. K. Folland, L. V. Alexander, D. P. Rowell, E. C. Kent, and A. Kaplan, 2003: Global analyses of sea surface temperature, sea ice, and night marine air temperature since the late nineteenth century. $J$. Geophys. Res., 108, 4407, doi:10.1029/2002JD002670.

Reppin, J., F. A. Schott, J. Fisher, and D. Quadfasel, 1999: Equatorial currents and transports in the upper central Indian Ocean: Annual cycle and interannual variability. J. Geophys. Res., 104, 15 495-15 514.

Reverdin, G., D. Cadet, and D. Gutzler, 1986: Interannual displacements of convection and surface circulation over the equatorial Indian Ocean. Quart. J. Roy. Meteor. Soc., 112, 43-46.

Reynolds, R. W., and T. M. Smith, 1994: Improved global sea surface temperature analyses using optimal interpolation. J. Climate, 7, 929-948.
Saji, N. H., B. N. Goswami, P. N. Vinayachandran, and T. Yamagata, 1999: A dipole mode in the tropical Indian Ocean. $\mathrm{Na}$ ture, 401, 360-363.

Schneider, N., A. J. Miller, and D. W. Pierce, 2002: Anatomy of North Pacific decadal variability. J. Climate, 15, 586-605.

Schreiber, T., and A. Schmitz, 1996: Improved surrogate data for nonlinearity tests. Phys. Rev. Lett., 77, 635-638.

Simmons, A. J., and Coauthors, 2004: Comparison of trends and variability in CRU, ERA-40 and NCEP-NCAR analyses of monthly-mean surface air temperature. ERA_40 Project Report Series 18, 42 pp. [Available online at http:// www.ecmwf.int/publications.]

Smith, T. M., and R. W. Reynolds, 2004: Improved extended reconstruction of SST (1854-1997). J. Climate, 17, 2466-2477.

Solomon, A., J. P. McCreary, R. Kleeman, and B. Klinger, 2003: Interannual and decadal variability in an intermediate coupled model of the Pacific region. J. Climate, 16, 383-405.

Susanto, R. D., A. L. Gordon, and Q. Zheng, 2001: Upwelling along the coasts of Java and Sumatra and its relation to ENSO. Geophys. Res. Lett., 28, 1599-1602.

Vinaychandran, P. N., N. H. Saji, and T. Yamagata, 1999: Response of the equatorial Indian Ocean to an unusual wind event during 1994. Geophys. Res. Lett., 26, 1613-1616.

Watanabe, M., and M. Kimoto, 2000: Atmosphere-ocean thermal coupling in the North Atlantic: A positive feedback. Quart. J. Roy. Meteor. Soc., 126, 3343-3369.

—, and F. F. Jin, 2003: A moist linear baroclinic model Coupled dynamical-convective response to El Niño. J. Climate, 16, 1121-1139.

Webster, P. J., A. M. Moore, J. P. Loschnigg, and R. R. Leben, 1999: Coupled oceanic-atmospheric dynamics in the Indian Ocean during 1997-98. Nature, 401, 356-360.

Xie, P., and P. Arkin, 1996: Analyses of global monthly precipitation using gauge observations, satellite estimates, and numerical model predictions. J. Climate, 9, 840-858.

- , H. Annamalai, F. A. Schott, and J. P. McCreary, 2002: Structure and mechanisms of south Indian Ocean climate variability. J. Climate, 15, 867-878.

Yamagata, T., S. Behera, S. A. Rao, Z. Guan, K. Ashok, and N. H. Saji, 2003: Comments on "Dipoles, temperature gradient, and tropical climate anomalies." Bull. Amer. Meteor. Soc., 84, 1418-1422.

Yu, L., and M. Rienecker, 1999: Mechanisms for the Indian Ocean warming during the 1997-98 El Niño. Geophys. Res. Lett., 26, $735-738$.

— and - 2000: Indian Ocean warming of 1997-1998. J. Geophys. Res., 105, $16923-16939$.

Zhang, Y., J. M. Wallace, and D. Battisti, 1997: ENSO-like interdecadal variability: 1990-93. J. Climate, 10, 1004-1020. 